\title{
Relationship Between Summer Extreme Precipitation Anomaly in Central Asia and Surface Sensible Heat Variation on the Central-Eastern Tibetan Plateau
}

hui wang ( $\nabla$ wanghui123@nuist.edu.cn)

NUIST: Nanjing University of Information Science and Technology https://orcid.org/0000-0001-67726277

Jie Zhang

NUIST: Nanjing University of Information Science and Technology

Lian Chen

Fudan University

Dongliang Li

NUIST: Nanjing University of Information Science and Technology

\section{Research Article}

Keywords: Tibetan Plateau, Central Asia, Extreme Precipitation, Sensible Heat Flux, Drought

Posted Date: November 3rd, 2021

DOI: https://doi.org/10.21203/rs.3.rs-574468/v1

License: (c) (i) This work is licensed under a Creative Commons Attribution 4.0 International License.

Read Full License 


\section{Abstract}

In the context of global warming, the frequency and intensity of extreme weather and climate events have increased, especially in Central Asia (CA). In this study, we investigate the characteristics of Summer Extreme Precipitation (SEP) in CA and its relationship with the Surface Sensible Heat (SSH) variation over the Central-Eastern Tibetan Plateau (CETP). Our results suggest that the distribution of SEP in CA is extremely uneven, and the SEP threshold ranges from 2 to $32 \mathrm{~mm}, 80 \%$ of them are concentrated in the range of $4-10 \mathrm{~mm}$. Both the total amount of SEP and the number of SEP days show significant increasing trends, with the climatic tendencies of $4.4 \mathrm{~mm} /$ decade and 0.4 day/decade, respectively. The SSH anomalies over the CETP can affect the SEP and the summer drought in CA by regulating the strength of the SAH and the subtropical jet over CA. The strong SSH anomalies over the CETP in late spring (April-May) can lead to the anomalously strong SAH in summer, anomalously weak subtropical westerly jet over CA and anomalously strong subtropical high over north Africa and the Arabian Peninsula. In addition, the Ural ridge strengthens, the CA trough weakens, and the northern CA is controlled by an abnormal warm high-pressure ridge with less anomalous water vapor convergence. Therefore, the SEP in northern CA will be abnormally less and the summer drought intensifies. Whereas, when the SSH over the CETP is anomalously weak in late spring, the key circulation characteristics are quite the opposite, at the same time, the anomalous water vapor from the Arctic, North Atlantic and western Pacific converges in northern CA and northern Xinjiang, China, which are conducive to the generation of widespread extreme precipitation and alleviates the summer drought in these regions.

\section{Introduction}

Central Asia (CA) is a typical arid and semi-arid climatic region located in the Eurasia inland with complex topography and dry climate, which is also a key region of China's national initiatives of "Silk Road" and "One Belt, One Road". Recently, the transboundary cooperation has been increasing between CA and its neighboring countries, therefore the climate change around CA has been attracting more and more international attention (Chen et al.2016; Peng et al. 2019; Zhu et al.2020).

CA exhibits obvious climatic variability and fragile ecosystem (Li et al. 2015; Zhang et al. 2016). Previous studies have shown that the temperature in CA rises much faster than the global mean temperature (Chen et al. 2009; Hu et al. 2014). This rapid warming trend has led to significant variation in the spatiotemporal patterns of extreme precipitation in CA (Chen et al.2011; Trenberth, et al. 2015; Alexander, 2016; Hu et al. 2016; Zhang et al. 2019a). The frequency and intensity of extreme weather and climate events have increased, and the losses caused by meteorological disasters have intensified, seriously affecting the natural ecological environment and the socio-economic sustainable development in the region (Lioubimtseva et al. 2009; Donat et al.2016; Li et al. 2017; Xenarios et al. 2019). Therefore, it is of great practical significance and scientific value to study the characteristics and causes of the extreme precipitation in CA. 
So far, the difficulties in predicting the extreme precipitation in CA are mainly due to the lack of systematic understanding of its variation patterns and the atmospheric circulation configurations influencing the extreme precipitation (Bothe et al. 2012; Li and Wang, 2018; Shang et al.2020). Precipitation-related circulation is vital for addressing these issues. The precipitation in CA is mainly dominated by the mid-latitude westerlies, with unique climatic characteristics, which is significantly different from the situation in East Asia with the domination of monsoon circulations (Schiemann et al. 2009; Liu et al. 2018; Yin et al. 2014; Watanabe and Yamazaki, 2014). Previous studies have proved that the precipitation in CA was mainly affected by the strength of the westerly jet stream and the spatiotemporal variations of the North Atlantic Oscillation (NAO) (Aizen et al. 2001; Filippi et al. 2014; Xu et al. 2016; Wei et al. 2017; Liu et al. 2017a; Sun et al. 2019a). In addition, the summer extreme precipitation in $\mathrm{CA}$ is closely related to the water vapor transport from the North Atlantic Ocean and the Indian Ocean (Bothe et al. 2012).

CA is adjacent to the northwest of the Tibetan Plateau (TP). Numerous studies have shown that the thermal and dynamical effects of the large topography of the TP play an important role in regulating the Asian monsoon system and the atmospheric circulation in the northern hemisphere (Ye and Wu,1998; Wu and Zhang,1998; Duan and Wu,2005; Zhou et al. 2009; Duan et al.2011; Ma and Ma, 2016; Liu et al. 2017b; Huang et al. 2019; Zhang et al. 2019b). However, there is limited research on the influence of the TP on the CA climate (Zhang et al. 2021). It is unclear whether the surface thermal anomalies of the TP can affect the extreme precipitation in $\mathrm{CA}$, and whether the physical mechanism of thermal influence of the TP on the climate of CA is the same as that of East Asian (EA) monsoon climate regions? Therefore, this paper starts with the variations of the Surface Sensible Heat (SSH) over the CETP to investigate the influence of its surface thermal anomalies on the Summer Extreme Precipitation (SEP) in CA and the key circulation processes. This study can provide theoretical basis for predicting the SEP in CA, and contribute to scientifically reducing the risk of extreme precipitation disasters and ensuring the socioeconomic sustainable development.

The subsequent sections are organized as follows. The study area, data and identification method of extreme precipitation are introduced in section 2. The features of SEP in CA are analyzed in section 3. The influences of the SSH variations over the CETP on the SEP anomalies in CA and the key circulation systems are described in section 4 and section 5. Finally, section 6 presents the main conclusions and discussion.

\section{Study Area, Data, And Methodology}

\subsection{Study area}

The study area covers five Central Asian countries (i.e., Kazakhstan, Kyrgyzstan, Tajikistan, Uzbekistan and Turkmenistan) and Xinjiang in China, lies between $48^{\circ} \mathrm{E}-95^{\circ} \mathrm{E}$ and $35^{\circ} \mathrm{N}-52^{\circ} \mathrm{N}$, and has a total area of 5.65 million $\mathrm{km}^{2}$ (Fig. 1). Since it is located in the hinterland of Eurasia, especially the Pamirs and Tibetan Plateau, with an elevation of above 4000 meters, form a natural barrier in the southeastern 
margin, blocking the warm and wet air flow of the Indian Ocean and the Pacific Ocean from entering CA (Bothe et al. 2012), the climate of this region is typical of the continental climate of temperate desert and grassland characterized by sharp temperature differences, intensive evaporation, and dry and rainless environments (Li et al. 2015; Zhang et al. 2019a). The geomorphological landscapes of the five countries in CA are mainly deserts, oases and mountains in the south, including the Kyzylkum Desert, the Karakum Desert, the Turan Depression and the Pamirs, and grasslands, plains and hills in the north, including the Caspian Despression, the Turgay Valley and Kazakh Hills, largely influenced by the NAO and westerly circulation. Meanwhile, the geomorphology in Xinjiang is characterized by a basin-and-range pattern. The Altai Mountains, Tianshan Mountains, and Kunlun Mountains are located in the northern, middle, and southern parts of the region, respectively, with the Junggar Basin and Tarim Basin positioned between these mountains (Zhang et al. 2019a). The Tianshan Mountains divide Xinjiang into two regions, Southern Xinjiang and Northern Xinjiang. Southern Xinjiang is located in the arid desert zone with the annual precipitation less than $100 \mathrm{~mm}$, and the Taklimakan Desert, which is the world's second largest mobile desert, positioned there. Northern Xinjiang is dominated by mountainous climate, affected by water vapor from the Atlantic and Arctic Oceans, with the annual precipitation about $150-200 \mathrm{~mm}$ and mainly concentrated in summer.

The TP which is located in the southeast of CA plays an important role in regulating the atmospheric circulation around it as a result of its high mean elevation of $4 \mathrm{~km}$, huge size of greater than 2.5 million $\mathrm{km}^{2}$ and variety of complex landscapes (Liu et al.2012; Zhang et al. 2019b; Yu et al. 2021). Due to the geomorphological landscapes in the western TP are mostly mountainous and deserts and sparsely populated, the observations of meteorological stations are mainly concentrated in the Central-Eastern TP (CETP). There are 70 relatively evenly distributed meteorological stations used in this study (as shown in Fig. 1).

\subsection{Data}

The daily precipitation data during 1982-2018 used in this paper is from the National Oceanic and Atmospheric Administration (NOAA) Climate Prediction Center (CPC), with a grid spacing of $0.5^{\circ} \times 0.5^{\circ}$ (https://climatedataguide.ucar.edu/climate-data/cpc-unified-gauge-based-analysis-global-daily-

precipitation; Chen et al. 2008). Previous studies have indicated that this dataset has a good performance in CA (Rana et al. 2017).

The monthly gridded global Palmer Drought Severity Index (PDSI) data during 1982-2014 used in this paper is from the National Center for Atmospheric Research (NCAR), with a grid spacing of $2.5^{\circ} \times 2.5^{\circ}$ (https://psl.noaa.gov/data/gridded/data.pdsi.html; Dai et al. 2004). The PDSI uses readily available temperature and precipitation data to estimate relative dryness. It is a standardized index that generally spans -10 (dry) to +10 (wet). The PDSI has been reasonably successful at quantifying long-term drought. As it uses temperature data and a physical water balance model, it can capture the basic effect of global warming on drought through changes in potential evapotranspiration (Dai et al. 2004). 
To calculate SSH flux, the monthly measurements of air temperature at $1.5 \mathrm{~m}$ above ground level (a.g.I.) from a sheltered thermometer $\left(T_{a}\right)$, ground surface temperature at $0 \mathrm{~cm}\left(T_{g}\right.$, measured using a thermometer where one half is horizontally exposed above ground, and the other half is horizontally interred), wind speed at $10 \mathrm{~m}$ a.g.I. $(U)$, and station surface pressure $\left(P_{s}\right)$ at 70 stations (see Figure 1$)$ on the CETP during 1982-2018 are used in this paper, which derive from the Chinese surface historical basic meteorological data sets version 3.0 from China Meteorological Administration (CMA). This data sets meet the standards of World Meteorological Organization (WMO)and comprises observations of 20 variables from more than 2,000 stations, all of which have been subject to quality control (Ren et al. 2012).

The Global Inventory Modeling and Mapping Studies (GIMMS) Normalized Difference Vegetation Index (NDVI) dataset (http://ecocast.arc.nasa.gov/data/pub/-gimms/3g/) is used herein to determine the underlying surface types and estimate the bulk transfer coefficients for heat at the CMA stations on the CETP. It has a 15-day temporal frequency, a 1/12-degree spatial resolution and a temporal span from July 1981 to December 2018. A detailed description of this dataset can be found in Zhu et al. (2013). Moreover, the NCEP-DOE (National Centers for Environmental Prediction-Department of Energy) reanalysis data is also used herein to describe the characteristics of atmospheric circulation conditions. The Niño 3.4 Index is employed to describe the influence of the El Niño-Southern Oscillation (ENSO) on the relationship between the SEP and the summer drought in CA and the SSH over the CETP, which is collected from CPC (https://www.cpc.ncep.noaa.gov/data/indices/-ersst5.nino.mth.91-20.ascii).

\subsection{Methods}

According to the standards of WMO, the extreme precipitation threshold at each grid point in CA is determined by using the international percentile method. First, the non-precipitation days during 19822018 are removed at all the grid points. Then, the daily precipitation data in summer (June-August) of each year are sorted in an ascending order at each grid, and the 37-year average of the 90th percentile is taken as the threshold of extreme precipitation at that grid point. Finally, the number of days with daily precipitation greater than or equal to the threshold of extreme precipitation in summer is taken as the number of SEP days, and the cumulative precipitation on the SEP days is the total amount of SEP. This method is widely used in the studies of extreme precipitation events (Bonsal et al, 2001; Xiao et al, 2016).

The bulk transfer method for deriving SSH has been widely utilized in TP-related studies (Ye,1982; Chen et al.1985; Ye and Wu,1998; Duan and Wu, 2005; Yang et al. 2009, 2011; Duan et al. 2011; Zhu et al. 2017; Wang and Li, 2018). It is as follows: $H=\rho_{s} c_{P} C_{h} U\left(T_{g}-T_{a}\right)(1)$

where $c_{p}$ is the specific heat capacity at a constant pressure (1004.07 $\left.\mathrm{J} \mathrm{kg}^{-1} \mathrm{k}^{-1}\right) ; C_{h}$ is the bulk transfer coefficient for heat; $U$ is the wind speed at $10 \mathrm{~m}$ a.g.I. $(\mathrm{m} / \mathrm{s}) ; T_{g}$ is the ground surface temperature $(\mathrm{K}) ; T_{a}$ is the air temperature $(\mathrm{K})$; and $\rho_{s}$ is the air density $\left(\mathrm{kg} \mathrm{m}^{-3}\right): \rho_{s}=P_{s} / R_{d} T_{a}(2)$

where $P_{s}$ is station pressure $\left(\mathrm{P}_{\mathrm{a}}\right)$ and $R_{d}$ is specific gas constant of dry air $\left(287.05 \mathrm{~J} \mathrm{~kg}^{-1} \mathrm{k}^{-1}\right)$. 
It is worthy of note that $C_{h}$ plays a key role in determining the SSH flux. It has been attracting the attention of many scientists. Chen and Wong (1984) developed a parameterization scheme using data obtained by the First Tibet Plateau Meteorological Experiment (TIPMEX) to estimate 10-day mean $C_{h}$ values for sites $>2800 \mathrm{~m}$ above sea level (a.s.l.). Zhao and Chen (2000) developed a multiple-parameter regression to parameterize $C_{h}$ and applied the parameterization to several TP stations. Yang et al. (2011) estimated the daily mean sensible heat flux over the TP from CMA station data using a physical scheme that is based on the Monin-Obukhov similarity theory and turbulence measurements (Yang et al. 2009, hereafter called the Yang scheme). Numerous evidences show that the value of $C_{h}$ varies widely on different land cover classes and in different seasons (Wang and Ma, 2011; Wang et al. 2019). Due to the complex topography and harsh environmental conditions, direct observation data from field experiments on the TP are particularly scarce, the determination of $C_{h}$ is a very complicated problem. Thus, in the process of deriving SSH by the bulk transfer method, many researches take $C_{h}$ as a constant value (e.g., 0.004 in the TP), without considering its seasonal variations and regional differences (Chen et al. 2019).

Recently, Wang et al. (2019) developed a new parameterization scheme using GIMMS-NDVI dataset and field micrometeorological observations on the CETP. This parameterization scheme takes into account the different meadow types on the CETP, and results suggest it is capable of reflecting the variations of $C_{h}$ at the regional scale in four seasons. Therefore, this parameterization scheme is applied to estimate $C_{h}$ for the CETP in this study. It is as follows:

$$
C_{h}=\left\{\begin{array}{lll}
-0.0045 N D V^{2}+0.0074 N D V I+0.0021 & \text { when } 0.50 \leq I_{S M}<1 & \text { for long meadow } \\
0.0062 N D V I^{2}-0.0020 N D V I+0.0021 & \text { when } 0.35 \leq I_{S M}<0.50 & \text { for short meadow (3) } \\
0.0120 N D V V^{2}-0.0015 N D V I+0.0029 & \text { when } 0<I_{S M}<0.35 & \text { for sparse meadow }
\end{array}\right.
$$

where $I_{S M}$ is the value of summer months (June-September) mean NDVI, when the value of $I_{S M}$ is greater than 0.50 , the underlying surface is defined as a long meadow; when $I_{S M}$ is in the range of $0.35-0.50$, the underlying surface is defined as a short meadow; and when $I_{S M}$ is less than 0.35 , the underlying surface is defined as a sparse meadow.

First, the $I_{S M}$ of each CMA station was calculated using the NDVI dataset to determine the underlying surface type. Then, the monthly values of $C_{h}$ and SSH fluxes at 70 meteorological stations during the period of 1982-2018 were calculated using Eq. (3) and Eq. (1) respectively. Evidences show that the values of $C_{h}$ calculated by Eq. (3) range from $0.0025-0.0050$, with obvious seasonal variations and spatial differences, which are smaller in winter and higher in summer, and in the southeast are higher than that in the central-northern TP; the SSH fluxes calculated by Eq. (1) consistent with the results of Yang scheme in terms of the interannual variation and trend characteristics, which can better represent the climatic characteristics of the SSH changes over CETP (Wang et al. 2019).

The mathematical statistics analysis methods used in this paper include regression, correlation, partial correlation and composite analysis, and a 5 years high-pass Lanczos filter ( Duchon, 1979; Sun et al. 
2019b; Yu et al. 2021) was applied to these datasets to extract the signals of interannual variability.

\section{Features Of The Sep In Ca}

Figure 2 presents the distribution of the extreme precipitation threshold and the proportion of grid points with different threshold ranges in CA. It shows that the SEP thresholds in CA vary between 2 and $32 \mathrm{~mm}$, with significant regional differences. The thresholds are within $4-10 \mathrm{~mm}$ at $80 \%$ of the stations. The larger values are mainly located in the western and northeastern Kazakhstan, especially in the Caspian Depression and West Siberian Plain, and around the Tianshan Mountains in central Xinjiang, China and the Kunlun Mountains in the south.

The spatial distributions of the total amount of SEP and the number of SEP days in CA are shown in Figure 3a-b, which are quite similar with each other. The key areas of SEP are in the northern CA and the Tianshan Mountains, with the average SEP days about 7 days and the total amount of precipitation over $90 \mathrm{~mm}$. Central and southern CA has less extreme precipitation in summer, with the total amount of extreme precipitation less than $20 \mathrm{~mm}$ and the extreme precipitation days of less than 2 days.

The spatial distribution of the climate tendency rates of the total amount of SEP in CA is shown in Figure $3 \mathrm{c}$, it shows that the total amount of SEP in CA has an increasing trend in general, and $24.8 \%$ of the stations with the increasing rates more than $5 \mathrm{~mm} /$ decade, only $3.8 \%$ of the stations has a significant decreasing trend. This also confirms the previous findings that most Asian drylands have been experiencing warm and wet conditions since the 1980 s (Shi et al. 2003). Comparing Fig. 3c and Fig. 3a shows that in the regions with a significant increasing trend in extreme precipitation, such as the northeast part of Kazakhstan and the Tianshan Mountains, are coincident with the areas with more extreme precipitation in Figure 3a, while in central and southern parts of CA with a slightly decreasing trend in extreme precipitation are coincident with the areas with less extreme precipitation in Figure $3 a$. These results imply that the dry areas are getting drier and wet areas are getting wetter in CA, which also means that the extreme events such as droughts and extreme precipitations are occurring more frequently in this region and will also result in a greater threat to the vulnerable ecosystems and human society of CA.

Over the last 37 years, both the total amount of SEP and the number of SEP days have been increasing in $\mathrm{CA}$, with the climatic tendencies of $4.4 \mathrm{~mm} /$ decade and 0.4 day/decade, respectively, passing the t-test at a $99 \%$ confidence level (i.e., $p<0.01$ ). The results are similar to the findings about extreme precipitation in other regions. For example, the increase and intensification of extreme precipitation have been observed in East Asia, South America, North America and Oceania (Zhai et al. 2005; Pryor, et al. 2009; You et al. 2011; Skansi, et al. 2013; Ren et al. 2015), which is mainly related to the significant global warming (Xu, et al, 2018; Yun, et al. 2019). The frequent occurrence and intensification of extreme events caused by the climate warming are becoming a prominent issue in the climate change (IPCC, 2014).

\section{Relationship Between The Ssh Over The Cetp And The Sep In Ca}


Previous studies have shown that SSH over the TP is the dominant source of diabatic heating and reaches its maximum during the boreal spring (Liu et al. 2015; Duan et al. 2017; Zhao et al. 2018; Chen et al. 2019). The infuence of TP thermal forcing on interannual variation of the Asian summer monsoon has been well addressed (Wang et al. 2008; Lau and Kim 2018). There is a significant positive correlation between the intensity of spring-summer TP heat source and summer monsoon precipitation in the Yangtze River valley and a negative correlation in southern and northern China (Hsu and Liu 2003; Cui et al. 2015). Then, what is the relationship between the SEP in CA and the thermal effect of the TP? What is the key atmospheric circulation system for this relationship? A diagnostic analysis of their relationship will be performed to clarify this issue. The correlation coefficients between the regional average SSH in different periods from April to July over the CETP and the SEP in CA are calculated (Table 1). It is shown that there are stable and significant negative correlations between the SSH from late spring to early summer over the CETP and the SEP in CA, with significant negative correlations between the SSH in April-May (AM), May-June (MJ) and April-July (AMJJ) and the SEP in CA $(p<0.01)$, and the bimonthly correlation in AM (-0.51) is better than that in $\mathrm{MJ}(-0.44)$ and June-July $(J J,-0.34, P<0.05)$, which is comparable to the relationship in AMJJ (-0.53). This is mainly because the SSH over the TP in May is the strongest and its absolute variability is the highest in a through year (Yang et al. 2009; Liu et al. 2015; Zhao et al. 2018; Chen et al. 2019). The South Asia (SA) and TP monsoon begin to onset in early June (Bei et al. 2016; Han et al. 2019), then precipitation on the plateau begins to increase, leading to a significant decrease in SSH flux in JJ. Therefore, the relationship between the plateau SSH transport and the SEP in CA declines at this time.

Table 1

The correlation coefficients and partial correlation coefficients between the SEP in CA and the regional average SSH over the CETP and the Niño3.4 in different periods from April to July (\# represents partial correlation coefficient)

\begin{tabular}{|lllll|}
\hline Period & \multicolumn{2}{l}{ The correlation coefficients } & \multicolumn{2}{l|}{ Partial correlation coefficients } \\
\cline { 2 - 5 } & SSH & Niño3.4 & SSH\# & Niño3.4\# \\
\hline AM & $-0.51^{\star \star}$ & -0.11 & $-0.50^{\star *}$ & 0.07 \\
\hline MJ & $-0.44^{\star *}$ & $-0.33^{\star}$ & $-0.34^{\star}$ & -0.16 \\
\hline JJ & $-0.34^{\star}$ & $-0.42^{\star *}$ & -0.23 & $-0.35^{\star}$ \\
\hline AMJJ & $-0.53^{\star *}$ & -0.30 & $-0.45^{\star *}$ & -0.04 \\
\hline \multirow{2}{*}{ * ** Statistical significance above the 95 and $99 \%$ confidence levels, respectively. } \\
\hline
\end{tabular}

Due to the ENSO is a dominant signal of the climate system in terms of interannual variability and is an important factor in regulating the interannual variation of precipitation of the EA and SA in spring and summer (Mao and Wu 2007; Deng et al. 2016; Yu et al. 2021). Considering that the ENSO anomaly might influence the SEP in CA, we investigate the correlation coefficients between the Niño3.4 in different 
periods from April to July and the SEP in CA (Table 1). The correlation coefficient between the Niño3.4 in $\mathrm{AM}$ and the SEP in CA is only -0.11 , indicating that the AM Niño3.4 might not be correlated with the SEP in CA. But the bimonthly correlation improves significantly in $\mathrm{MJ}(-0.33, \mathrm{P}<0.05)$ and $\mathrm{JJ}(-0.42, \mathrm{P}<0.01)$, which indicates that there is also a significant negative correlation between ENSO and the SEP in CA in $\mathrm{MJ}$ and $\mathrm{JJ}$, and the relationship in $\mathrm{JJ}$ even exceeds that of the SSH over the CETP. In order to explore the leading factor affecting the SEP in CA, we calculated the partial correlation coefficients in different periods from April to July between the SSH over the CETP and the SEP in CA with the Niño3.4 signal removed and the partial correlation coefficients between the Niño3.4 and the SEP in CA with the SSH over the CETP signal removed, respectively (Table 1). It shows that their partial correlation coefficients decrease to a certain extent compared with the original correlation coefficients, especially the partial correlation coefficients between the AM, MJ and AMJJ Niño3.4 and the SEP in CA with the SSH over the CETP signal removed decrease significantly and the values become very small. That is to say, the partial correlation between the ENSO and the SEP in CA becomes very poor, since removing the effect of the SSH over the CETP on the SEP in CA. By contrast, the partial correlations between the AM, MJ and AMJJ SSH over the CETP and the SEP in CA with removing the Niño3.4 signal still present significant negative correlations $(p<0.05)$, especially the partial correlation coefficient between the AM SSH over the CETP and the SEP in CA with removing the Niño3.4 signal is $-0.50(P<0.01)$, nearly the same as their original correlation (-0.51). From the interannual variation of the SSH over the CETP in AM (Fig. 4), it can be seen that the SSH evolution with removing the Niño3.4 signal is very consistent with the original SSH, and the correlation coefficient between them reaches $0.94(\mathrm{P}<0.001)$. Moreover, there is a good inverse relationship between the SSH over the CETP and the SEP in CA. That is, the anomalously strong AM SSH over the CETP corresponds to less SEP in CA, especially in 1986, 1987, 1991, 1998, 2004 and 2014. Otherwise, it corresponds to more extreme precipitation, especially in 1984, 1988, 2002, 2013 and 2016. It's worth noting that the partial correlation coefficient between the JJ Niño3.4 and the SEP in CA is -0.35 $(P<0.05)$, which is better than that of between the JJ SSH over the CETP and the SEP in CA with removing the Niño3.4 signal, indicating that the relationship between the ENSO and the SEP in CA has been enhanced with the decrease of SSH transport over the CETP in early summer.

Then, what is the spatial distribution of the relationship between the SSH over the CETP and the SEP in CA? Where are the key areas? Does the SSH over the CETP also influence the summer drought in CA? The relationship between the summer PDSI and the AM SSH over the CETP is also explored. The spatial distributions of the correlation coefficients and the partial correlation coefficients with removing the Niño3.4 signal between the SEP and the summer PDSI in CA and the AM SSH over the CETP are shown in Figure 5. It shows that there is a significant negative correlation between the SSH over the CETP and the SEP in most parts of CA (Fig. 5a), which is consistent with the result in Table 1. The key areas with negative correlations are mainly in northeastern and northwestern CA and northern Xinjiang in China. Nevertheless, there are also some small areas with significant positive correlations, including Tajikistan, Kyrgyzstan and central-northern part of Kazakhstan. Due to the extreme precipitation in southern CA is very rare, these grids with less than 20 samples of extreme precipitation data are removed in the correlation analysis between the SEP in CA and the SSH over the CETP. So, there are large blank areas in 
southern CA in Figure 5a-b. The spatial distribution of the correlation coefficients between the summer PDSI in CA and the AM SSH over the CETP represents a south-north dipole mode, with significant positive correlations in southern CA, and negative correlations in northern CA and northern Xinjiang in China (Fig. 5c), which resembles the correlation map between the SEP in CA and the AM SSH over the CETP, indicating that the strong SSH over the CETP in late spring facilitates less (more) SEP in northern (southern) CA, and the in situ summer drought will intensify (alleviate), and vice versa. The spatial patterns of the partial correlation coefficients with removing the Niño3.4 signal (Fig. 5b, d) are similar to the original correlation patterns between the SEP and the summer PDSI in CA and the AM SSH over the CETP (Fig. 5a, C), and the partial correlation coefficient is more significant than the original correlation coefficient between the summer PDSI and the SSH over the CETP in northern CA and northern Xinjiang in China. Therefore, we can conclude that in the late spring (before the TP monsoon onset), the SSH over the CETP affect the SEP and the summer drought in CA, which is independent of the ENSO.

\section{Key Circulation Systems}

The previous analysis shows that there is a good correlation between the AM SSH over the CETP and the SEP and the summer drought in CA. Then, how is the connection established? Regression analyses between the AM SSH over the CETP and the bimonthly geopotential height fields at 500-hPa, 300-hPa and 100-hPa from April to August are conducted (Fig. 6). According to the thermal adaptation theory (Wu et al. 2007, 2016; Liu et al. 2017b), the anomalously enhanced thermal effect of the plateau surface will cause the lower atmosphere to be heated, converge and rise, forming a thermal low pressure at the lower layer over the TP. Accordingly, the geopotential height field will rise anomalously in the upper troposphere, forming a warm high pressure center. In Figure 6, with the anomalously enhanced sensible heat on the CETP in AM, the 500-hPa geopotential height is anomalously low in AM (Fig. 6a1), the 300-hPa geopotential height over the eastern TP is anomalously high (Fig. 6a2), and the 100-hPa geopotential height anomaly is further enhanced (Fig. 6a3). In MJ, the geopotential height anomaly at 300-hPa over the eastern plateau and the low-latitude areas is further intensified (Fig. 6b2), and it is significantly enhanced at 100-hPa (Fig. 6b3). In the following JJ and JA, the anomalous intensification of the 100-hPa geopotential height develops further, with the significant anomaly dominating in the south of $40^{\circ} \mathrm{N}$. Previous studies indicated that the SSH transportation over the TP from spring to summer has a good persistence (Wang and $\mathrm{Li}, 2018$ ). When the SSH is anomalously intense in spring, the SSH transportation in the following summer will be abnormally strong. Thus, the anomalously strong SSH on the TP in AM will be transmitted from the lower to the upper layers through the continuous heating to the atmosphere. It will eventually be preserved in the upper troposphere for a long time, resulting in an anomalously strong South Asia High (SAH) afterwards, and vice versa. The SAH, also known as the Tibetan high (Yeh and Gao,1979), is the strongest and most stable circulation system dominating at $100-\mathrm{hPa}$ in the northern hemisphere in summer. Numerous studies have indicated that the formation and development of the SAH are closely related to the thermal effect of the TP. Both diagnostic analysis and numerical simulation have confirmed that the sensible and latent heating of the TP play an essential role in the formation and evolution of the SAH (Wu et al.1999; Liu et al. 2004; Ren et al. 2019; Zhang et al. 2019b). To verify 
whether the SSH anomalies over the CETP regulate the SEP in CA by influencing the SAH, the composite analysis is carried out for the atmospheric circulations in the northern hemisphere in summer, investigating the differences between strong and weak SSH years, providing an insight into the physical processes and the key circulation systems in which the plateau sensible heat influences the SEP and the summer drought in CA. According to the time series of AM SSH over the CETP with removing the Niño3.4 signal, and taking one standard deviation as the abnormal standard, 6 strong years $(1986,1987,1991$, 1995, 2012 and 2014) and 6 weak years (1984, 1992, 1994, 2002, 2013 and 2016) are selected separately. Due to 1987, 1991, 1992 and 2016 are strong El Nino years, considering the possible influence of ENSO signal on atmospheric circulation, the cases in these years are removed. Finally, 4 strong years (1986, 1995, 2012 and 2014) and 4 weak years (1984, 1994, 2002 and 2013) are selected separately in the composite analysis.

Figure 7 shows the distribution of summer average geopotential height at 100-hPa during 1982-2018 and the composite geopotential height anomaly fields at 100-hPa in years with anomalously strong and anomalously weak SSH in AM. It shows that the summer average SAH is located over the TP and the Iranian plateau (Fig. 7a). When the SSH over the CETP is anomalously strong in late spring (AM), the100$\mathrm{hPa}$ geopotential height in summer is significantly increased over the TP and the lower latitudes south of it (Fig. 7b), and the SAH is anomalously strong and eastward (Fig. 7a). Conversely, when the SSH is anomalously weak over the CETP, the geopotential height is anomalously low over the southern plateau and the low latitudes and anomalously high over CA, northern China and the Japanese archipelago (Fig. 7c), and the SAH is anomalously weak and westward (Fig. 7a). The results are consistent with that in Figure 6, that is, the strong SSH anomaly will result in an anomalously strong SAH afterwards, and vice versa.

Figure 8 illustrates the distribution of summer subtropical westerly jet. As shown in the distribution of summer average zonal wind at 200-hPa during 1982-2018 (Fig. 8a), the average subtropical westerly jet in summer is located in $36^{\circ} \mathrm{N}-45^{\circ} \mathrm{N}$, with the jet center $(\mathrm{U}>25 \mathrm{~m} / \mathrm{s})$ in the north of the TP. When the SSH over the CETP in late spring (AM) is anomalously strong, the westerly anomalies over the TP and the regions east of it strengthen, and easterly anomalies appear over CA (Fig. 8b2), so the subtropical westerly jet is anomalously weak over CA and anomalously strong over the north part of TP, and the location of the westerly jet is slightly southward (Fig. 8b1), compared with the climate mean (Fig. 8a). When the plateau SSH is anomalously weak in late spring (AM), there is an opposite situation. In $15^{\circ} \mathrm{N}-$ $35^{\circ} \mathrm{N}$, the easterly anomalies significantly strengthen over West Africa, the Arabian Peninsula, the Iranian plateau, the TP and its east, and the Japanese archipelago. In $35^{\circ} \mathrm{N}-50^{\circ} \mathrm{N}$, the westerly anomalies intensify over the Mediterranean, the south of Ural Mountains, northern CA and northern China (Fig. 8c2). Thus, the subtropical westerly jet is anomalously strong and northward with the northern boundary of the jet center $(\mathrm{U}>25 \mathrm{~m} / \mathrm{s})$ near to $48^{\circ} \mathrm{N}$ (Fig. 8c1). The variations of the subtropical westerly jet from April to July in strong and weak years are also investigated (figures not shown), and the results are similar to those in summer, that is, the strong (weak) SSH anomaly over the CETP facilitates the subtropical westerly jet to be anomalously weak (strong) and southward (northward) over CA. 
The 500-hPa geopotential height and temperature fields (Fig. 9) show that, when the SSH over the CETP in late spring (AM) is anomalously strong (Fig. 9b1), the geopotential height is anomalously high over the south of $30^{\circ} \mathrm{N}$ and northern CA in summer. The subtropical high over northern Africa, the Arabian Peninsula and the western Pacific is anomalously strong, the Ural ridge strengthens and CA trough weakens (Fig. 9a, b1). The northern CA is controlled by an abnormal warm high-pressure ridge (Fig. 9b1, b2), which is not conducive to the generation of extreme precipitation in the region. Conversely, when the SSH over the CETP in late spring (AM) is anomalously weak (Fig. 9c1), the geopotential height is anomalously low over the south of $30^{\circ} \mathrm{N}$ and northern CA in summer. The subtropical high over northern Africa, the Arabian Peninsula and the western Pacific is anomalously weak, the Ural ridge weakens and the CA trough strengthens (Fig. 9a, $\mathrm{C} 1$ ). The northern CA and northern Xinjiang in China are controlled by an abnormal cold low-pressure trough (Fig. 9c1, c2), which is conducive to the generation of extreme precipitation in these regions. Moreover, the western TP and its vicinity are controlled by an abnormal warm high-pressure ridge, which is not conducive to the generation of extreme precipitation in Tajikistan and Kyrgyzstan of southeastern CA.

The 850-hPa wind field (Fig. 10) also indicates that when the SSH over the CETP is anomalously strong in late spring (AM), the anticyclonic circulation anomaly in northern CA is strengthened in summer (Fig. $10 \mathrm{a}, \mathrm{b})$. The distributions of the moisture fluxes at different altitudes in troposphere and the whole layer moisture flux and their moisture divergence flux indicate that the anomalous water vapor from the Mediterranean and the North Atlantic flows into CA at the northern and eastern boundaries via the Barents Sea and the West Siberian plain, diverging in northern CA (Fig. 11a1-d1), which is not conducive the generation to the extreme precipitation and intensifies the summer drought in the region. Whereas, when the plateau SSH is anomalously weak (Fig. 10c), the CA and its adjacent regions are controlled by abnormal cyclonic circulation, which weakens the Ural ridge and strengthens the CA trough, facilitating water vapor to enter $\mathrm{CA}$ through the western and southern boundaries. The distribution of the moisture flux at lower troposphere $(925-\mathrm{hPa})$ indicates that the anomalous water vapor from the Arctic Ocean and the North Atlantic converges in southwestern CA through its western boundary (Fig. 11a2). Due to the terrain obstruction of the TP, Pamirs and Iranian plateaus, there is little water vapor entering the CA through the southern boundary in the lower troposphere. However, at the middle troposphere (700-hPa and $500-\mathrm{hPa}$ ), anomalous water vapor from the Western Pacific, the South China Sea and the Bay of Bengal entering CA through the southern boundary increases rapidly, and transported northward along the southwest airflow in front of the CA trough, then converges in the northern CA (Fig. 11b2-c2). The distribution of the whole layer moisture flux also shows that there are three water vapor sources entering $\mathrm{CA}$, that is, the water vapor from the Arctic and North Atlantic entering CA through the western boundary and the water vapor from the western Pacific, the South China Sea and the Bay of Bengal entering CA through the southern boundary, these anomalous water vapor converges in northern CA and northern Xinjiang, China (Fig. 11d2), which is conducive to the generation of widespread extreme precipitation and alleviates the summer drought in these regions.

To sum up, The SSH anomalies over the CETP can affect the SEP and the summer drought in CA by regulating the location and strength of the $\mathrm{SAH}$ and the subtropical jet over $\mathrm{CA}$. The strong SSH 
anomalies over the CETP in late spring (AM) can lead to the anomalously strong and eastward SAH in summer, anomalously weak subtropical westerly jet over CA and anomalously strong subtropical high over north Africa, the Arabian Peninsula and the western Pacific. In addition, the Ural ridge strengthens, the CA trough weakens, and the northern CA is controlled by an abnormal warm high-pressure ridge with less anomalous water vapor convergence. All these circulation characteristics are not conducive the generation to the extreme precipitation in the northern $\mathrm{CA}$, so in situ the summer drought will intensify. Whereas, the weak SSH anomalies over the CETP in late spring (April-May) can result in the anomalously weak SAH in summer, anomalously strong and northward subtropical westerly jet, and the anomalously weak subtropical high in north Africa, the Arabian Peninsula and the western Pacific. In addition, the $\mathrm{CA}$ and its adjacent regions are controlled by abnormal cyclonic circulation, which weakens the Ural ridge and strengthens the $\mathrm{CA}$ trough, at the same time, the anomalous water vapor from the Arctic, North Atlantic, the western Pacific, the south China sea and the Bay of Bengal, converges in northern CA and northern Xinjiang, China, which is conducive to the generation of widespread extreme precipitation and alleviates the summer drought in these regions.

\section{Conclusions And Discussion}

In this study, the threshold, total amount of SEP and the number of SEP days in CA are calculated using the international percentile method and the relationship between the SEP and the summer drought in CA and the SSH transport over the CETP from late spring to early summer is discussed. The main conclusions are as follows.

The distribution of SEP in CA is extremely uneven, and the extreme precipitation threshold ranges from 2 $\mathrm{mm}$ to $32 \mathrm{~mm}$, with large regional differences. Both the total amount of SEP and the number of SEP days show significant increasing trends, with the climatic tendencies of $4.4 \mathrm{~mm} / \mathrm{decade}$ and 0.4 day/decade, respectively. Extreme weather events in CA are intensifying, with dry areas getting drier and wet areas getting wetter. The SSH over the CETP in late spring (April-May) is well related to the SEP and the summer drought in CA. Significant negative correlations are found in northwestern and northeastern CA and northern Xinjiang in China, that is, the anomalously strong (weak) SSH in late spring over the CETP will lead to anomalously less (more) SEP in northern CA and northern Xinjiang in China, and the in situ summer drought will be intensified (alleviated).

The SSH anomalies over the CETP can affect the SEP and the summer drought in CA by regulating the location and strength of the SAH and the subtropical jet over CA. When the SSH over the CETP is anomalously weak in late spring (AM), the key circulation factors leading to frequent SEP in northern CA are as follows: the anomalously weak $\mathrm{SAH}$, the subtropical westerly jet strengthened over the $\mathrm{CA}$, weakened over the TP and East Asia, the anomalously weak north Africa subtropical high, and the CA trough strengthened. In addition, there are three water vapor sources, that is, the water vapor from the Arctic and North Atlantic entering CA through the western boundary and the water vapor from the western Pacific, the South China Sea and the Bay of Bengal entering CA through the southern boundary, which provide sufficient water vapor conditions for the extreme precipitation in the northern CA. 
This study provides us with an insight into the influence of the TP thermal effect on the extreme climate and summer drought in CA. Previous studies have shown that the anomalously strong (weak) SSH over the TP in spring can lead to anomalously less (more) summer precipitation in the southern China (the Yangtze River valley) (Hsu and Liu 2003; Cui et al. 2015). This study also shows that the circulation systems over the EA are significantly different in the years with anomalously strong and weak SSH over the CETP. The anomalously weak SSH over the CETP in late spring can result in the anomalously weak subtropical high over the western Pacific in summer (Fig. 9a1,c1), the southern China is controlled by abnormal cyclonic circulation (Fig. 10c) and water vapor converging (Fig. 11a2-d2), while the Yangtze River valley and the Japanese Islands are controlled by anticyclonic circulation (Fig. 10c) and water vapor diverging (Fig. 11a2-d2), which are conducive to the summer precipitation generation in southern China, but not conducive to the summer precipitation generation in the Yangtze River valley and the Japanese Islands. These results indicate that the SSH anomaly over the CETP can affect the climate of CA and EA simultaneously, and the SSH variation in late spring over the CETP can be an effective predictor for the climate of CA and EA.

However, due to the complex topography of the TP, the SSH variation is inconsistent (Duan et al. 2011; Wang et al.2019). Thus, the key areas for the influence of the plateau SSH anomalies on the SEP and the summer drought in CA and the effective simplification of forecast indicators will be further investigated. In addition, some questions remain to be addressed. For example, whether the SEP and the summer drought in CA are mainly influenced by the surface thermal effect over the CETP, and whether the relationship is regulated by other external forcing factors, such as NAO. The NAO has been proven to be an important influence factor for the precipitation anomalies in $\mathrm{CA}$, and it also has a significant impact on the climate of the TP. Cui et al. (2015) pointed out that during the positive phase of the NAO in winter, it can excite a stable downstream Rossby wave train, inducing the Asian subtropical westerly jet to intensify and the India-Burma trough to deepen, and it also increases the snow depth over the TP in winter, followed by a positive SSH anomaly in spring in most areas of the TP. Other research has reported that the March surface air temperature over the TP is closely related to the February NAO and regulated by the phase of the Atlantic multi-decadal variability (Li et al. 2021). Therefore, the SEP in CA is directly influenced by the spring SSH over the TP, and may also be modulated by the winter SST anomalies in the North Atlantic. What are the synergetic effect and contribution rates of the NAO and the SSH over the CETP? These issues deserve further study.

\section{Declarations}

Competing interests: The authors declare no competing interests.

\section{Acknowledgments}

This work was supported by the Key Project of National Key Research and Development Program of China (2018YFC1507101), the Second Tibetan Plateau Scientific Expedition and Research (STEP) 
program (2019QZKK0103) and National Natural Science Foundation of China (NSFC) (U20A2098). We thank Nanjing Hurricane Translation for reviewing the English language quality of this paper.

\section{References}

1. Aizen EM, Aizen, VB, Melack, JM et al (2001) Precipitation and atmospheric circulation patterns at mid-latitudes of Asia. Int J Clim 21: 535-556. https://doi.org/10.1002/joc.626

2. Alexander LV (2016) Global observed long-term changes in temperature and precipitation extremes: A review of progress and limitations in IPCC assessments and beyond. Weather Clim Extreme 11: 416. https://doi.org/10.1016/j.wace.2015.10.007

3. Bai AJ, Li GP (2016) Climatology of monsoon precipitation over the Tibetan Plateau from 13-year TRMM observations. Theor Appl Climatol 126, 15-26. https://doi.org/10.1007/s00704-015-1555-2

4. Bonsal BR, Zhang X, Vincent LA et al (2001) Characteristics of daily and extreme temperatures over Canada囚J Clim 14: 1959囚1976. https://doi.org/10.1175/15200442(2001)014<1959:CODAET >2.0.CO;2

5. Bothe O, Fraedrich K, Zhu XH (2012) Precipitation climate of Central Asia and the large-scale atmospheric circulation. Theor Appl Climatol 108, 345-354. https://doi.org/10.1007/s00704-0110537-2

6. Chen FH, Huang W, Jin LY et al (2011) Spatiotemporal precipitation variations in the arid Central Asia in the context of global warming. Sci China Earth Sci 54:1812-1821. https://doi.org/10.1007/s11430-011-4333-8

7. Chen FH, Wang JS, Jin LY et al (2009) Rapid warming in mid-latitude central Asia for the past 100 years. Front Earth Sci China 3:42-50. https://doi.org/10.1007/s11707-009-0013-9

8. Chen L, Pryor SC, Wang H et al (2019). Distribution and variation of the surface sensible heat flux over the central and eastern Tibetan Plateau: Comparison of station observations and multireanalysis products. J Geophys Res Atmos, 124, 6191-6206. https://doi.org/10.1029/-2018JD030069

9. Chen LX, Reiter ER, Feng ZQ (1985) The atmospheric heat source over the Tibetan Plateau: MayAugust 1979. Mon Weather Rev 113: 1771-1790. https://doi.org/10.1175/15200493(1985) $113<1771:$ TAHSOT>2.0.CO;2

10. Chen MY, Shi W, Xie PP et al (2008) Assessing objective techniques for gauge based analyses of global daily precipitation. J Geophys Res Atmos 113, D04110, http://dx.doi.org/-10.1029/2007JD009132.

11. Chen W, Wong D (1984) A preliminary study on the computational method of 10-day mean sensible heat and latent heat on the Tibetan Plateau collected works of the Qinghai-Xizang plateau meteorological experiment (series 2) (in Chinese). Beijing: Science Press, pp 35-45

12. Chen YN, Li Z, Li WH et al (2016) Water and ecological security: Dealing with hydroclimatic challenges at the heart of China's Silk Road. Environ Earth Sci, 75: 881. 
https://doi.org/10.1007/s12665-016-5385-z

13. Cui YF, Duan AM, Liu YM et al (2015) Interannual variability of the spring atmospheric heat source over the Tibetan Plateau forced by the North Atlantic SSTA. Clim Dyn, 45: 1617-1634. https://doi.org/10.1007/s00382-014-2417-9

14. Dai AG, Trenberth K E, Qian TT (2004) A Global Dataset of Palmer Drought Severity Index for 18702002: Relationship with Soil Moisture and Effects of Surface Warming, J Hydrometeorology, 5(6):1117-1130. https://journals.ametsoc.org/view/journals/hydr/5/6/-jhm386_1.xml

15. Deng MY, Lu RY, Chen W et al (2016) Interannual variability of precipitation in May over the South Asian monsoonal region. Int J Climatol 36(4):1724-1732. https://doi.org/10.1002/-joc.4454

16. Donat MG, Lowry AL, Alexander LV et al (2016) More extreme precipitation in the world's dry and wet regions. Nat Clim Change 6:508-513. https://doi.org/10.1038/NCLIMATE2941

17. Duan AM, Li F, Wang MR et al (2011) Persistent weakening trend in the spring sensible heat source over the Tibetan Plateau and its impact on the Asian summer monsoon. J Clim 24 (21): 5671-5682. https://doi.org/10.1175/JCLI-D-11-00052.1

18. Duan AM, Sun RZ, He JH (2017) Impact of surface sensible heating over the Tibetan Plateau on the western Pacifc subtropical high: a land-air-sea interaction perspective. Adv Atmos Sci 34(2):157168. https://doi.org/10.1007/s00376-016-6008-zg.

19. Duan AM, Wu GX. (2005) Role of the Tibetan Plateau thermal forcing in the summer climate patterns over subtropical Asia. Clim Dyn, 24: 793-80. https://doi.org/10.1007/s00382-004-0488-8

20. Filippi L, Palazzi E, von Hardenberg J et al (2014) Multidecadal variations in the relationship between the NAO and winter precipitation in the HinduKush-Karakoram. J Clim 27: 7890-7902. https://doi.org/10.1175/JCLI-D-14-00286.1

21. Han Y, Ma WQ, Ma YM et al (2019) Variations of Surface Heat Fluxes over the Tibetan Plateau before and after the Onset of the South Asian Summer Monsoon during 1979-2016. J Meteorol Res 33, 491-500. https://doi.org/10.1007/s13351-019-8616-x

22. Hsu HH, Liu X (2003) Relationship between the Tibetan plateau heating and east Asian summer monsoon rainfall. Geophys Res Lett 30(20):2066. https://doi.org/10.1029/2003gl017909

23. Hu ZY, Li QX, Chen X et al (2016) Climate changes in temperature and precipitation extremes in an alpine grassland of Central Asia. Theor Appl Climatol 126:519-531. https://doi.org/10.1007/s00704-015-1568-x

24. Hu ZY, Zhang C, Hu Q et al (2014) Temperature changes in central Asia from 1979 to 2011 based on multiple datasets. J Clim 27:1143-1167. https://doi.org/10.1175/JCLI-D-13-00064.1

25. Huang JP, Chen W, Wen ZP et al (2019) Review of Chinese atmospheric science research over the past 70 years: Climate and climate change. Sci China Earth Sci 62: 1514-1550. https://doi.org/10.1007/s11430-019-9483-5

26. IPCC. (2014) Climate Change 2014: impacts, adaptation and vulnerability. Contribution of Working Group II to the fifth assessment report of the Intergovernmental Panel on Climate Change. Cambridge \& New York: Cambridge University Press,151 pp. 
27. Lau WKM, Kim KM (2018) Impact of snow darkening by deposition of light-absorbing aerosols on snow cover in the himalayastibetan plateau and infuence on the Asian summer monsoon: a possible mechanism for the blanford hypothesis. Atmosphere 9:438. https://doi.org/10.3390/-atmos9110438

28. Li CF, Zhang C, Luo GP et al (2015) Carbon stock and its responses to climate change in Central Asia. Glob Change Biol 21:1951-1967. https ://doi.org/10.1111/gcb.12846

29. Li J, Wang B (2018) Predictability of summer extreme precipitation days over eastern China. Clim Dyn 51:4543-4554. https ://doi.org/10.1007/s0038 2-017-3848-x

30. Li JY, Li F, He SP et al (2021) The Atlantic Multidecadal Variability Phase Dependence of Teleconnection between the North Atlantic Oscillation in February and the Tibetan Plateau in March. J Clim 34(11):4227-4242. https://journals.ametsoc.org/view/journals/clim/-34/11/JCLI-D-20-0157.1

31. Li PY, Qian H, Zhou W (2017) Finding harmony between the environment and humanity: An introduction to the thematic issue of the Silk Road. Environ Earth Sci, 76: 105. https://doi.org/10.1007/s12665-017-6428-9.

32. Lioubimtseva E, Henebry GM (2009) Climate and environmental change in arid Central Asia: Impacts, vulnerability, and adaptations. J Arid Environ 73: 963-977. https://doi.org/10.1016/j.jaridenv. 2009.04.022.

33. Liu C, Liu YM, Liu BQ (2015) Comparison of six sensible heat fux datasets over the Iranian-Tibetan Plateaus. J Meteorol Sci 35(4):398-404. https://doi.org/10.3969/2014jms.0038

34. Liu H, Liu XD, Dong BW (2017a) Intraseasonal variability of winter precipitation over central Asia and the western Tibetan Plateau from 1979 to 2013 and its relationship with the North Atlantic Oscillation. Dynam Atmos Oceans 79, 31- 42. https://doi.org/10.1016/-j.dynatmoce.2017.07.001

35. Liu Y, Wu GX, Hong J et al (2012) Revisiting Asian monsoon formation and change associated with Tibetan Plateau forcing: Il. Change. Clim Dyn 39,1183-1195. https://doi.org/10.1007/s00382-0121335-y

36. Liu YM, Wang ZQ, Zhuo HF et al (2017b) Two types of summertime heating over Asian large-scale orography and excitation of potential-vorticity forcing II. Sensible heating over Tibetan-Iranian Plateau. Sci China Earth Sci 60: 733-744. https://doi.org/ 10.1007/s11430-016-9016-3

37. Liu YM, Wu GX, Ren RC (2004) Relationship between the subtropical anticyclone and diabatic heating. J Clim, 17 (4):682-698. https://doi.org/10.1175/15200442(2004)017$<0682$ :RBTSAA>2.0.CO;2

38. Liu YZ, Wu CQ, Jia R et al (2018) An overview of the influence of atmospheric circulation on the climate in arid and semi-arid region of Central and East Asia. Sci. China Earth Sci 61:1183-1194. https://doi.org/10.1007/s11430-017-9202-1

39. Ma WQ, Ma YM. (2016) Modeling the influence of land surface flux on the regional climate of the Tibetan Plateau. Theor Appl Climatol 125(1): 45-52. https://doi.org/10.1007/s00704-015-1495-x

40. Mao JY, Wu GX (2007) Interannual variability in the onset of the summer monsoon over the Eastern Bay of Bengal. Theor Appl Climatol 89(3-4):155-170. https://doi.org/10.1007/s00704-006-0265-1 
41. Peng DD, Zhou TJ, Zhang LX et al (2019) Detecting human influence on the temperature changes in central Asia. Clim Dyn, 53(7):4553-4568. https://doi.org/10.1007/s00382-019-04804-2

42. Pryor SC, Howe JA, Kunkel KW (2009) How spatially coherent and statistically robust are temporal changes in extreme precipitation in the contiguous USA? Int J Climatol, 29(1):31-45. https://doi.org/10.1002/joc.1696

43. Rana S, McGregor J, Renwick J (2017) Wintertime precipitation climatology and ENSO sensitivity over central southwest Asia. Int J Clim 37: 1494-1509. https://doi.org/10.1002/joc.4793

44. Ren RC, Zhu CD, Cai M (2019) Linking quasi-biweekly variability of the South Asian high to atmospheric heating over Tibetan Plateau in summer. Clim Dyn 53, 3419-3429. https://doi.org/10.1007/s00382-019-04713-4

45. Ren ZG, Zhang MJ, Wang SJ et al (2015) Changes in daily extreme precipitation events in South China from 1961 to 2011. J Geogr Sci 25: 58-68. https://doi.org/10.1007/s11442-015-1153-3

46. Ren ZH, Yu Y, Zou FL et al (2012) Quality detection of surface historical basic meteorological data. J Appl Meteorol Sci, 23(6): 739-747. (in Chinese)

47. Schiemann R, Lüthi D, Schä C (2009) Seasonality and interannual variability of the westerly jet in the Tibetan Plateau region. J Clim 22: 2940-2957. https://doi.org/10.1175/2008JCLI2625.1

48. Shang W, Li SS, Ren XJ et al (2020) Event-based extreme precipitation in Central-Eastern China: large-scale anomalies and teleconnections. Clim Dyn 54: 2347-2360. https://doi.org/10.1007/s00382-019-05116-1

49. Shi Y, Yu G (2003) Warm-humid climate and transgressions during 40-30 ka B.P. and their potential mechanisms. Quat. Sci., 23 (1), 1-11. https://doi. org/10.3321/j.issn:1001-7410.2003.01.001

50. Skansi MM, Brunet M, Sigró J et al (2013) Warming and wetting signals emerging from analysis of changes in climate extreme indices over South America. Global Planet Change 100: 295-307. https://doi.org/10.1016/j.gloplacha.2012.11.004

51. Sun RZ, Duan AM, Chen LL et al (2019b) Interannual variability of the north pacifc mixed layer associated with the spring Tibetan Plateau thermal forcing. J Clim 32(11):3109-3130. https://doi. org/10.1175/jcli-d-18-0577.1

52. Sun XQ, Li SL, Hong XW et al (2019a) Simulated Influence of the Atlantic Multidecadal Oscillation on Summer Eurasian Nonuniform Warming since the Mid-1990s. Adv Atmos Sci 36, 811-822. https://doi.org/10.1007/s00376-019-8169-z

53. Trenberth KE, Fasullo JT, Shepherd TG (2015) Attribution of climate extreme events. Nature Clim Change 5: 725-730. https://doi.org/10.1038/nclimate2657

54. Wang B, Bao Q, Hoskins B et al (2008) Tibetan plateau warming and precipitation changes in East Asia. Geophys Res Lett 35: L14702. https://doi.org/10.1029/2008gl034330

55. Wang H, Hu ZY, Li DL et al (2019) Estimation of the surface heat transfer coefficient over the eastcentral Tibetan Plateau using satellite remote sensing and field observation data. Theor Appl Climatol 138:169-183. https://doi.org/10.1007/s00704-019-02815-x 
56. Wang H, Li DL (2018) Decadal Variability in Summer Precipitation over Eastern China and its Response to Sensible Heat over the Tibetan Plateau since the Early 2000s. Int J Clim 38. https://doi.org/10.1002/joc.5903

57. Wang SZ, Ma YM (2011) Characteristics of land-atmosphere interaction parameters over the Tibetan Plateau. J Hydrometeorology 12(4):702-708. https://doi.org/10.1175/2010JHM-1275.1

58. Watanabe T, Yamazaki K (2014) The upper-level circulation anomaly over Central Asia and its relationship to the Asian monsoon and mid-latitude wave train in early summer. Clim Dyn 42: 24772489. https://doi.org/10.1007/s00382-013-1888-4

59. Wei W, Zhang RH, Wen M et al (2017) Relationship between the Asian westerly jet stream and summer rainfall over Central Asia and North China: Roles of the Indian Monsoon and the South Asian High. J Clim 30: 537-552. https://doi.org/10.1175/JCLI-D-15-0814.1

60. Wu GX, Duan AM, Liu YM et al (2015) Tibetan Plateau climate dynamics: recent research progress and outlook. Natl Sci Rev 2(1):100-116. https://doi.org/10.1093/nsr/nwu045

61. Wu GX, Liu YM, Liu P (1999) The effect of spatially on the formation and variation of subtropical high part:I scale analysis. Acta Meteor Sinica 57(3): 257-263 (in Chinese)

62. Wu GX, Liu YM, Zhang Q et al (2007) The influence of mechanical and thermal forcing by the Tibetan Plateau on Asian climate. J Hydrometeorology 8:770-789. https://doi.org/10.1175/-JHM609.1

63. Wu GX, Zhang YS (1998) Tibetan Plateau forcing and timing of south Asia monsoon and South China Sea Monsoon. Mon Weather Rev 126(4): 913-927. https://doi.org/10.1175/15200493(1998)126<0913:TPFATT>2.0.C0;2

64. Wu GX, Zhuo HF, Wang ZQ et al (2016) Two types of summertime heating over the Asian large-scale orography and excitation of potential-vorticity forcing I. Over Tibetan Plateau. Sci China Earth Sci 59(10):1996-2008. https://doi.org/10.1007/s1143 0-016-5328-2

65. Xenarios S, Gafurov A, Schmidt Vogt D et al. (2019) Climate change and adaptation of mountain societies in Central Asia: uncertainties, knowledge gaps, and data constraints. Reg Environ Change 19:1339-1352. https://doi.org/10.1007/s10113-018-1384-9

66. Xiao C, Wu PL, Zhang LX et al (2016) Robust increase in extreme summer rainfall intensity during the past four decades observed in China. Sci Rep 6: 38506. https://doi.org/10.1038/srep38506

67. Xu TT, Shi ZG, Wang HL et al (2016) Nonstationary impact of the winter North Atlantic Oscillation and the response of mid-latitude Eurasian climate. Theor Appl Climatol 124:1-14. https://doi.org/10.1007/s00704-015-1396-z

68. Xu WH, Li QX, Jones P et al (2018) A new integrated and homogenized global monthly land surface air temperature dataset for the period since 1900. Climate Dyn 50:2513-2536. https://doi.org/10.1007/s00382-017-3755-1

69. Yang K, Guo X, Wu B (2011) Recent trends in surface sensible heat flux on the Tibetan Plateau. Sci China Earth Sci 54: 19-28. https://doi.org/10.1007/s11430-010-4036-6

70. Yang K, Qin J, Guo XF et al (2009) Method development for estimating sensible heat flux over the Tibetan Plateau from CMA data. J Appl Meteorol Climatol 48(12):2474-2486. 
https://doi.org/10.1175/2009JAMC2167.1

71. Ye DZ (1982) Some aspects of the thermal influences of the Qinghai-Tibetan Plateau on the atmospheric circulation. Arch Met Geoph Biocl A 31: 205-220. https://doi.org/10.1007/BF02258032

72. Ye DZ, Wu GX (1998) The role of the heat source of the Tibetan Plateau in the general circulation. Meteorl and Atmos Phys 67:181-198. https://doi.org/10.1007/BF01277509

73. Yeh DZ, Gao YX (1979). Meteorology of the Qinghai-Xizang (Tibet) Plateau (in Chinese). Beijing: Science Press.

74. Yin ZY, Wang HL, Liu XD (2014) A comparative study on precipitation climatology and interannual variability in subtropical East Asia and Central Asia. J Clim 27:7830-7848. https://doi.org/10.1175/JCLI-D-14-00052.1

75. You QL, Kang SC, Aguilar E et al (2011) Changes in daily climate extremes in China and their connection to the large scale atmospheric circulation during 1961-2003. Clim Dyn 36: 2399-2417. https://doi.org/10.1007/s00382-009-0735-0

76. Yu W, Liu Y M, Yang XQ et al (2021). Impact of North Atlantic SST and Tibetan Plateau forcing on seasonal transition of springtime South Asian monsoon circulation. Clim Dyn 56, 559-579. https://doi.org/10.1007/s00382-020-05491-0

77. Yun X, Huang BY, Cheng JY et al (2019) A new merge of global surface temperature datasets since the start of 20th century. Earth Syst Sci Data 11:1629-1643. https://doi.org/10.5194/essd-11-16292019

78. Zhai PM, Zhang XB, Wan $\mathrm{H}$ et al (2005) Trends in total precipitation and frequency of daily precipitation extremes over China. J Clim 18:1096-1108. https://doi.org/10.1175/JCLI-3318.1

79. Zhang C, Lu DS, Chen X et al (2016) The spatiotemporal patterns of vegetation coverage and biomass of the temperate deserts in central Asia and their relationships with climate controls. Remote Sens Environ. 175:271-281. https://doi.org/10.1016/j.rse.2016.01.002

80. Zhang HX, Li WP, Li WJ (2019b) Influence of Late Springtime Surface Sensible Heat Flux Anomalies over the Tibetan and Iranian Plateaus on the Location of the South Asian High in Early Summer. Adv Atmos Sci 36:93-103. https://doi.org/10.1007/s00376-018-7296-2.

81. Zhang J, Ma QR, Chen HS et al (2021). Increasing Warm-Season Precipitation in Asian Drylands and Response to Reducing Spring Snow Cover over the Tibetan Plateau. J Clim 34, 8, 31293144. https://doi.org/10.1175/JCLI-D-20-0479.1

82. Zhang M, Chen YN, Shen YJ et al (2019a) Tracking climate change in Central Asia through temperature and precipitation extremes. J Geogr Sci 29:3-28. https://doi.org/10.1007/s11442-0191581-6

83. Zhao P, Chen LX (2000) Study on climatic features of surface turbulent heat exchange coefficients and surface thermal sources over the Qinghai-Xizang Plateau. Acta Meteorol Sin 14(1):13-29

84. Zhao Y, Duan AM, Wu GX (2018) Interannual variability of late-spring circulation and diabatic heating over the Tibetan Plateau associated with indian ocean forcing. Adv. Atmos. Sci. 35, 927-941 (2018). https://doi.org/10.1007/s00376-018-7217-4

Page 20/30 
85. Zhou X J, Zhao P, Chen J M et al (2009) Impacts of thermodynamic processes over the Tibetan Plateau on the Northern Hemispheric climate. Sci China Earth Sci 52: 1679-1693. https://doi.org/10.1007/s11430-009-0194-9

86. Zhu X, Wei ZG, Dong WJ et al (2020) Dynamical downscaling simulation and projection for mean and extreme temperature and precipitation over central Asia. Clim Dyn 54:3279-3306. https://doi.org/10.1007/s00382-020-05170-0

87. Zhu ZC, Bi J, Pan YZ et al (2013) Global data sets of vegetation leaf area index (LAl)3g and fraction of photo synthetically active radiation (FPAR) $3 \mathrm{~g}$ derived from global inventory modeling and mapping studies (GIMMS) normalized difference vegetation index (NDVI3g) for the period 1981 to 2011. Remote Sens 5(2):927-948. https://doi.org/10.3390/rs5020927

88. Zhu LH, Huang G, Fan G Z et al (2017) Evolution of surface sensible heat over the Tibetan Plateau under the recent global warming hiatus. Advances in Atmospheric Sciences 34(10): 1249-1262. https://doi.org/10.1007/s00376-017-6298-9

89. Duchon CE (1979). Lanczos Filtering in One and Two Dimensions, Journal of Applied Meteorology and Climatology, 18 (8), 1016-1022. https://doi.org/10.1175/15200450(1979)018$<1016$ :LFIOAT >2.0.CO;2

\section{Figures}

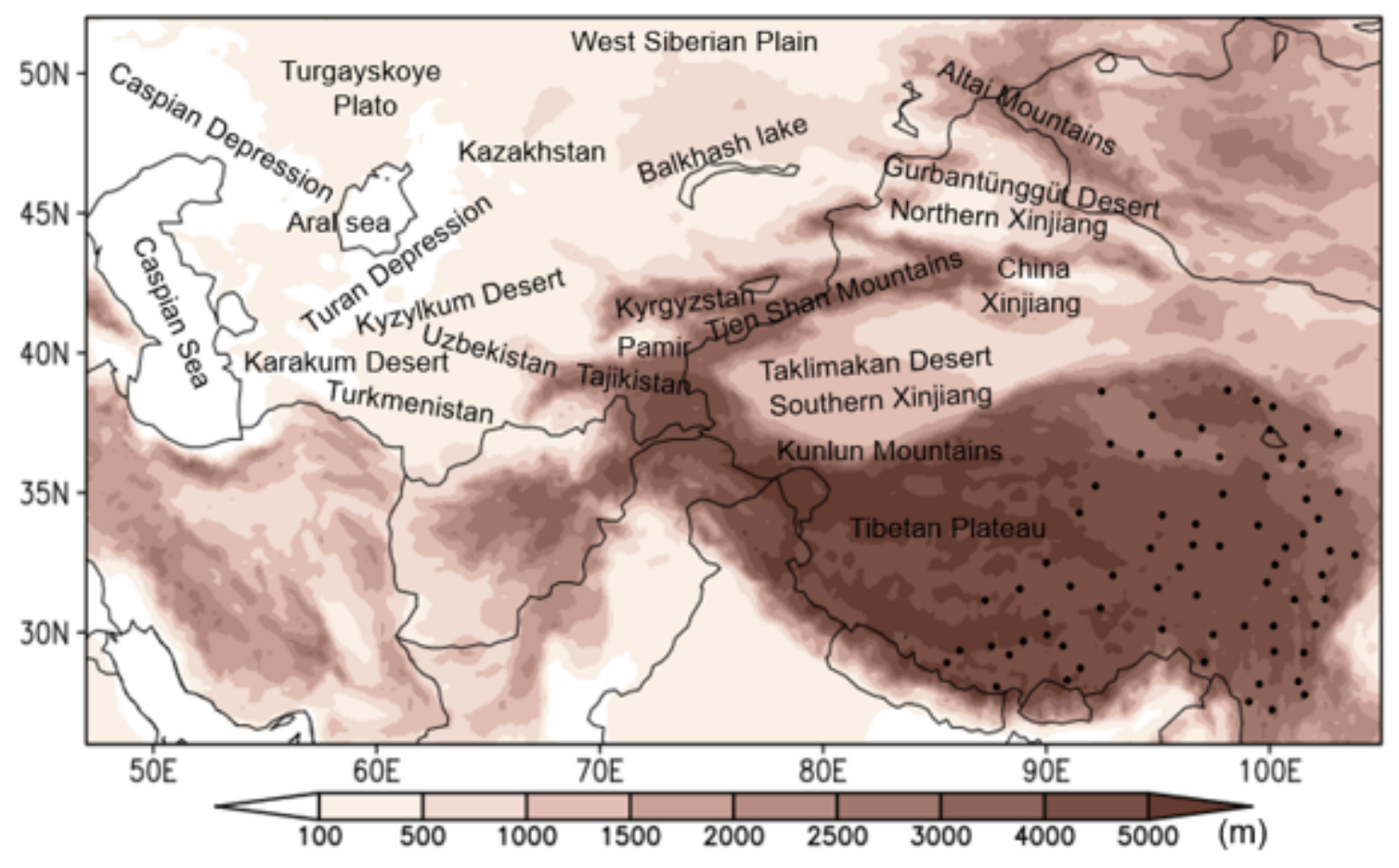

Figure 1

Locations of Central Asia and the meteorological stations on the Central-Eastern Tibetan Plateau 
(a)

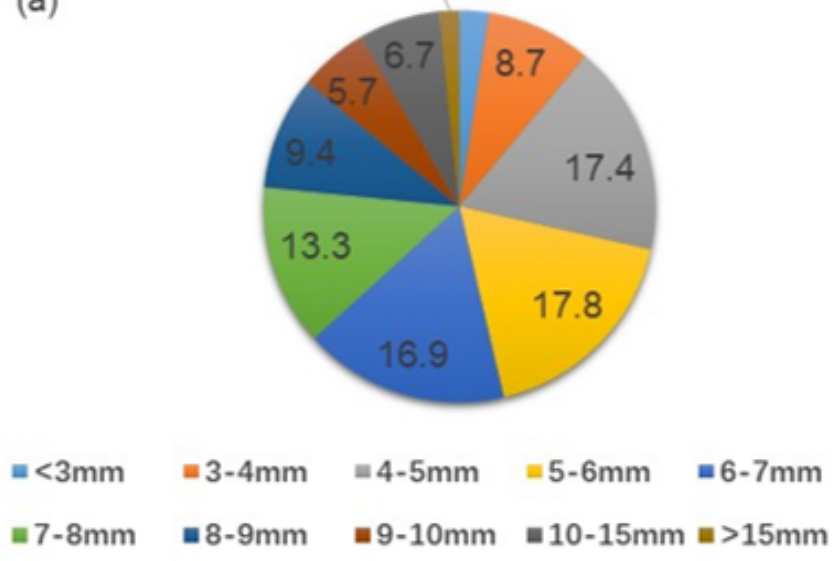

(b)

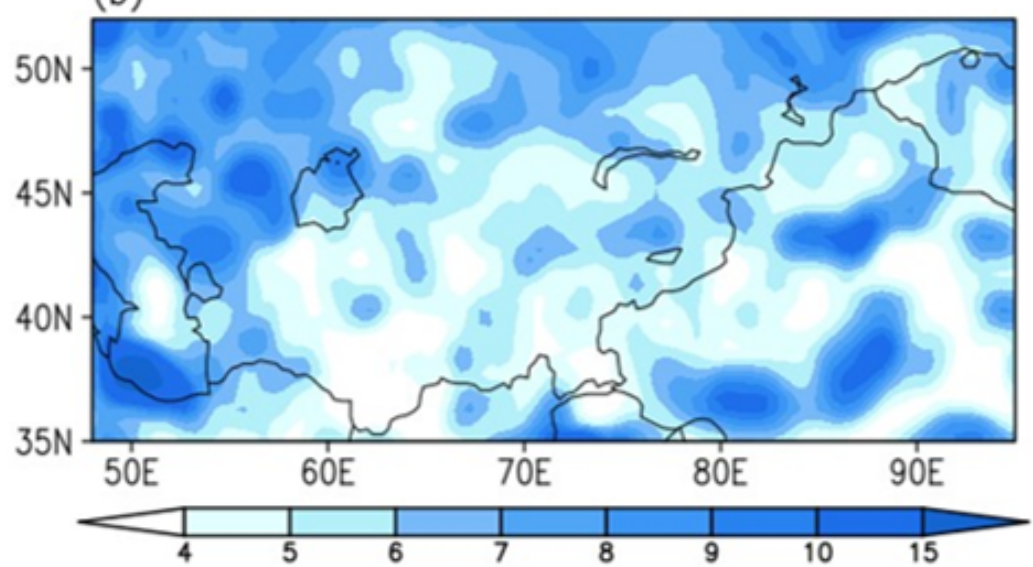

Figure 2

The proportion of grid points with different threshold ranges (a) and (b) distribution of the extreme precipitation threshold in CA.

(a)

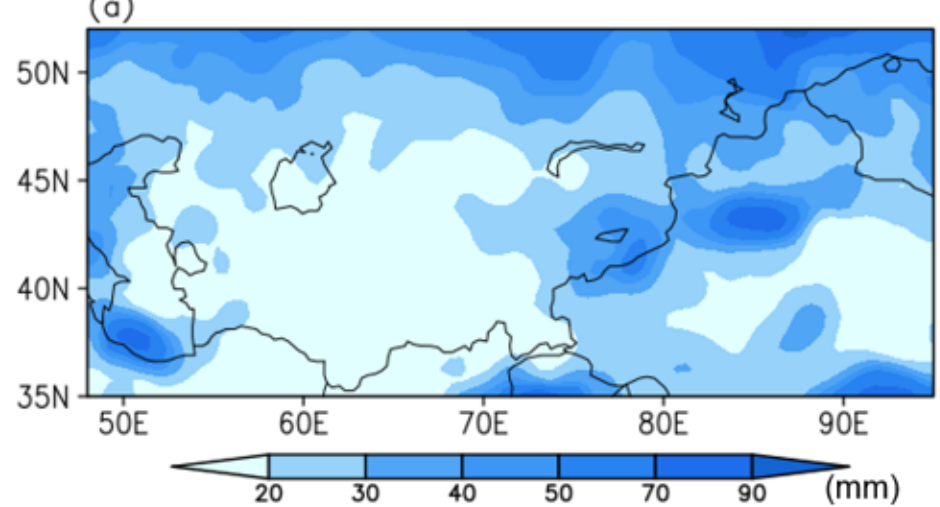

(c)

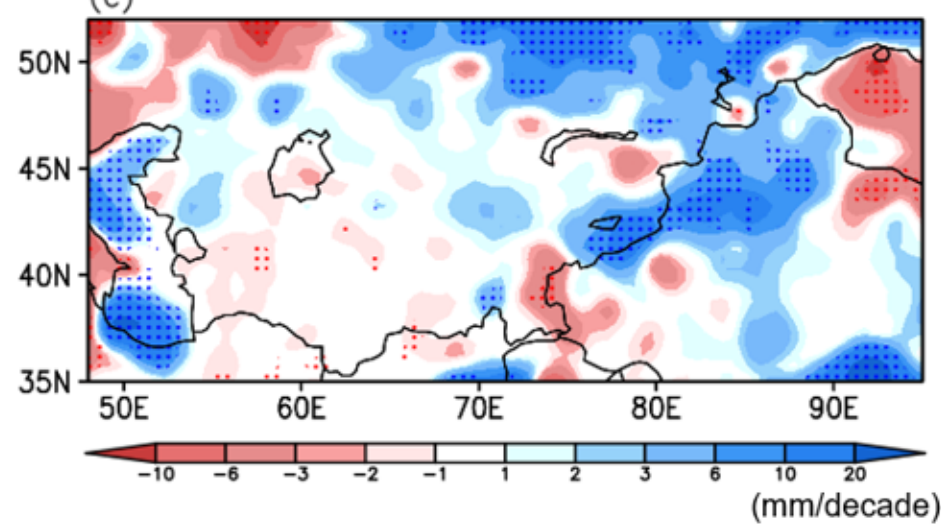

(b)

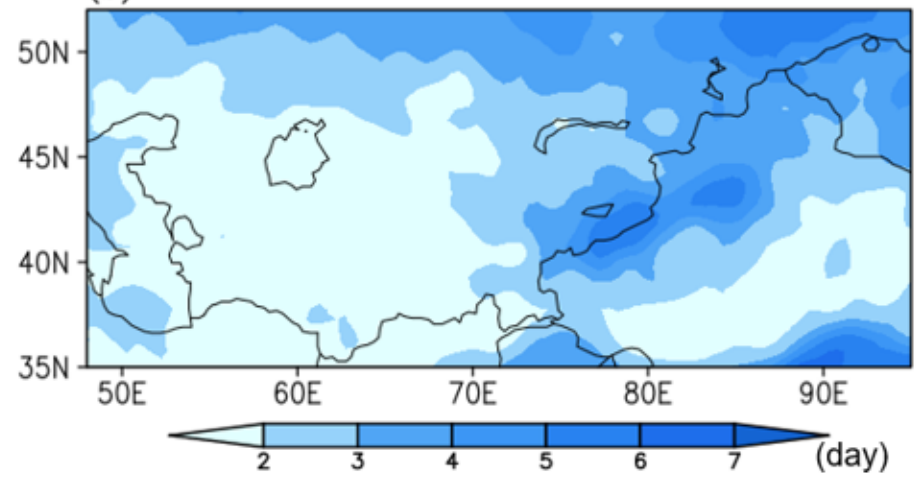

(d)

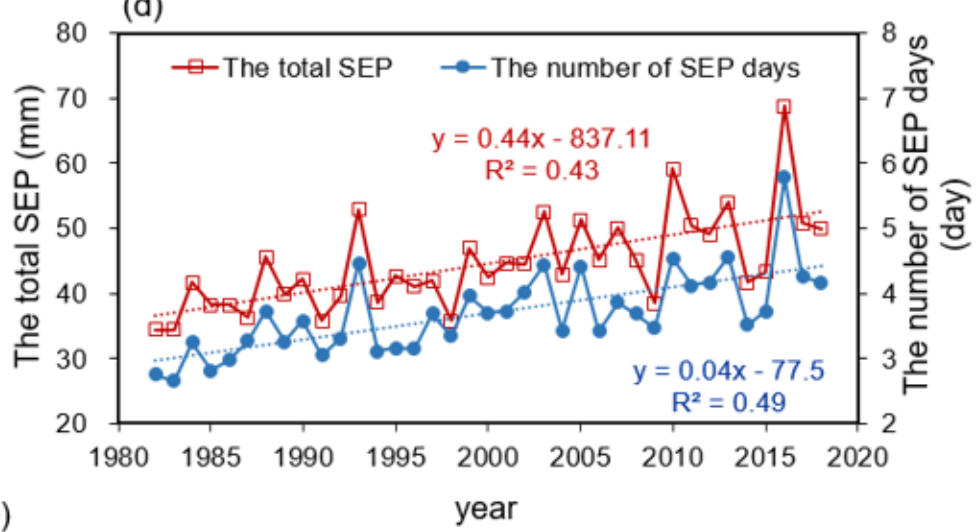

\section{Figure 3}

The spatial distribution of (a) the total SEP, (b) the number of SEP days and (c) the climate tendency rates of the total SEP, and (d) the interannual variations of the total SEP and the number of SEP days during 1982-2018. The red (blue) solid line is the total SEP (the number of SEP days), the red (blue) dotted line, formula and R2 in (d) are its trend line, linear regression and complex correlation coefficient, respectively. 


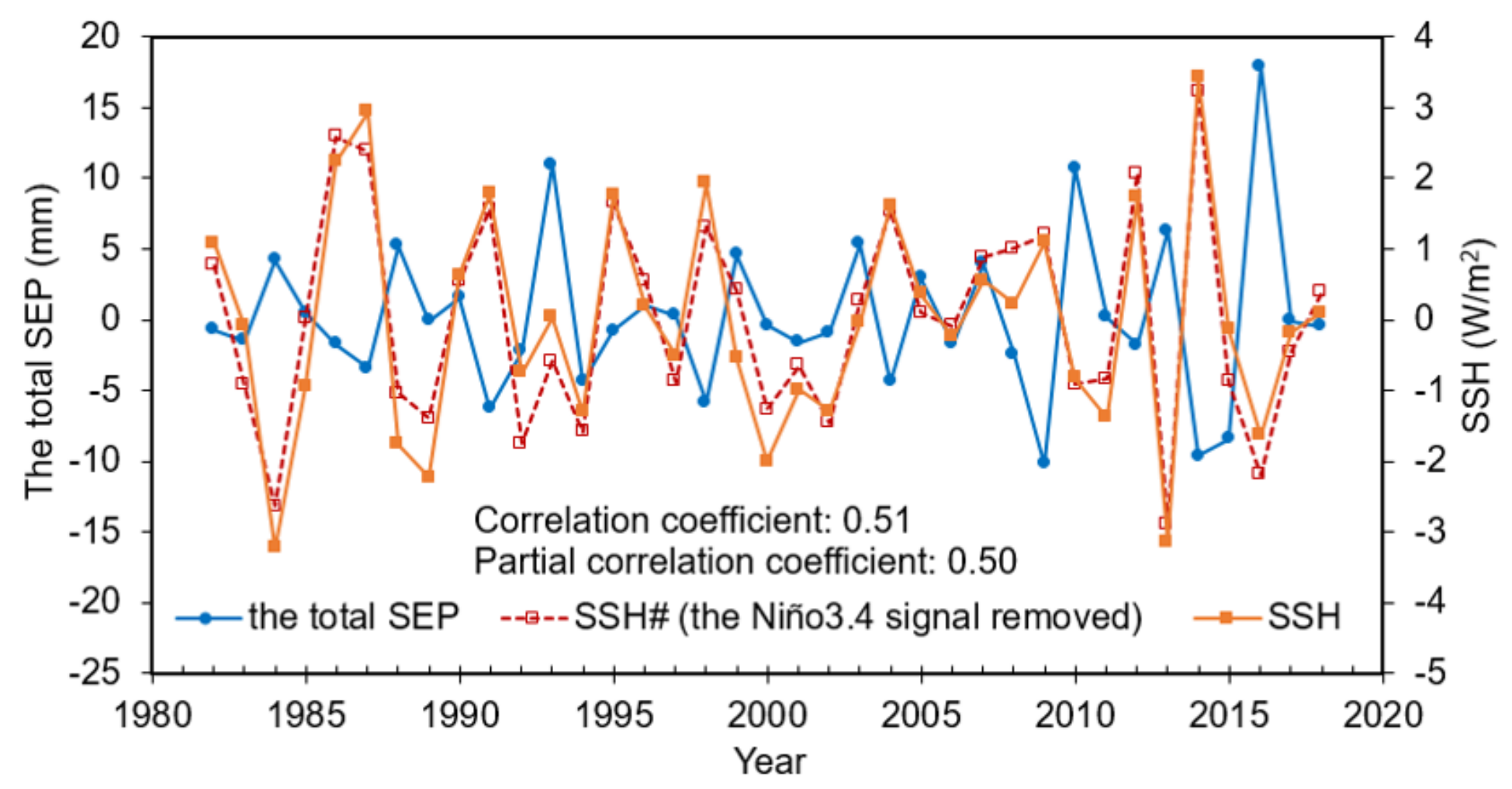

Figure 4

The interannual variations of the regional average SSH and SSH\# (the Niño3.4 signal removed) in AM over the CETP and the total SEP in CA during 1982-2018, the correlation coefficient and the partial correlation coefficient with removing the Niño3.4 signal between the SEP in CA and the AM SSH over the CETP are 0.51 and 0.50 , respectively. 
(a)SEP \& SSH correlation

(b)SEP \& SSH partial correlation

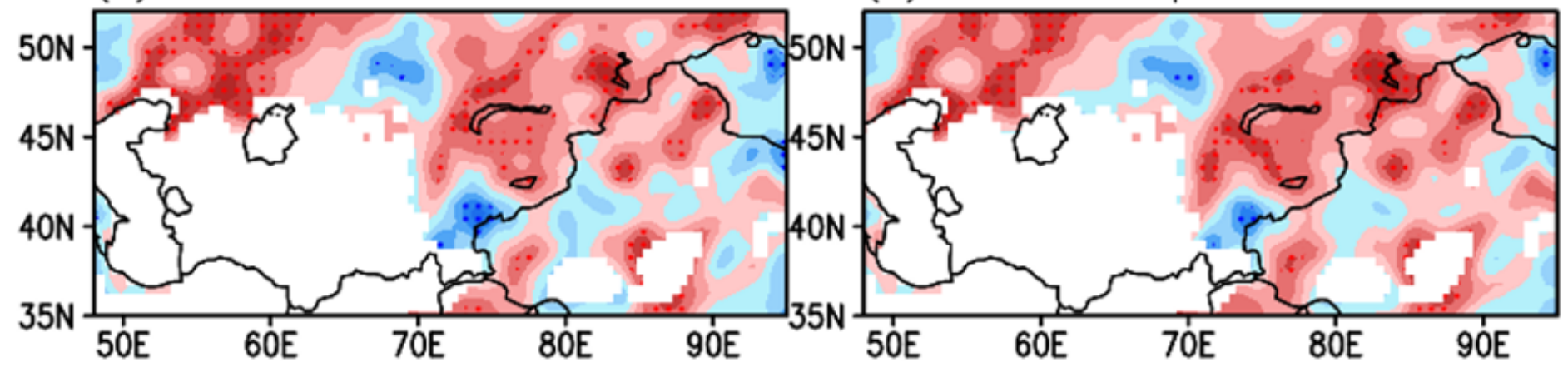

(c)PDSI \& SSH correlation

(d)PDSI \& SSH partial correlation

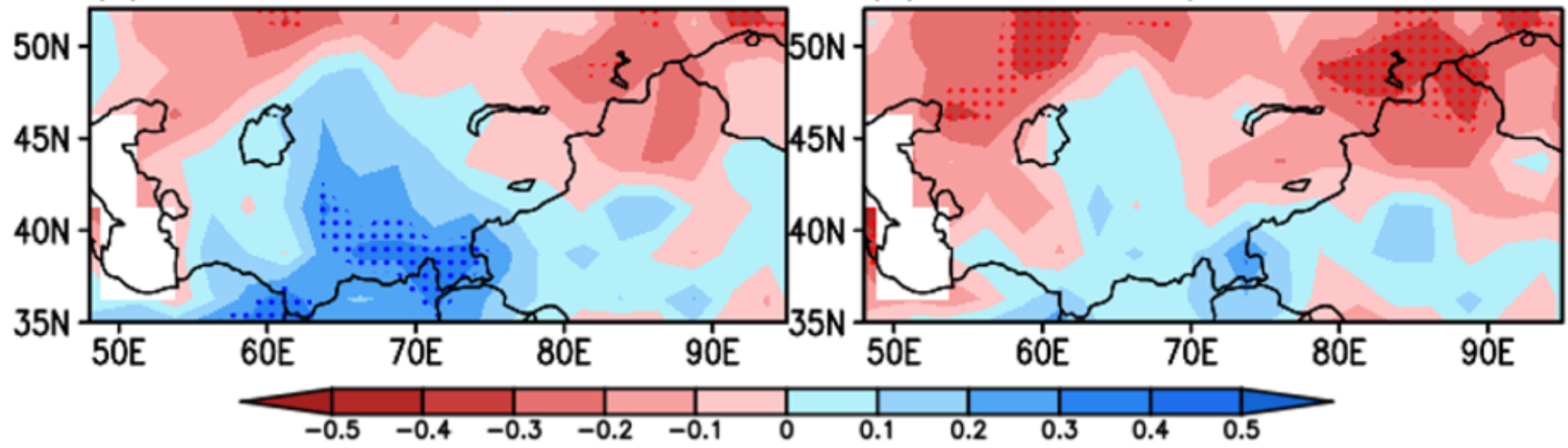

Figure 5

The spatial distributions of $(a, c)$ the correlation coefficients and $(b, d)$ the partial correlation coefficients with removing the Niño3.4 signal between $(a, b)$ the SEP and $(c, d)$ the summer PDSI in CA and the AM SSH over the CETP. The stippled areas in (a)-(d) indicate correlation above the $90 \%$ confidence level. 
(a1) AM $500 \mathrm{hPa}$
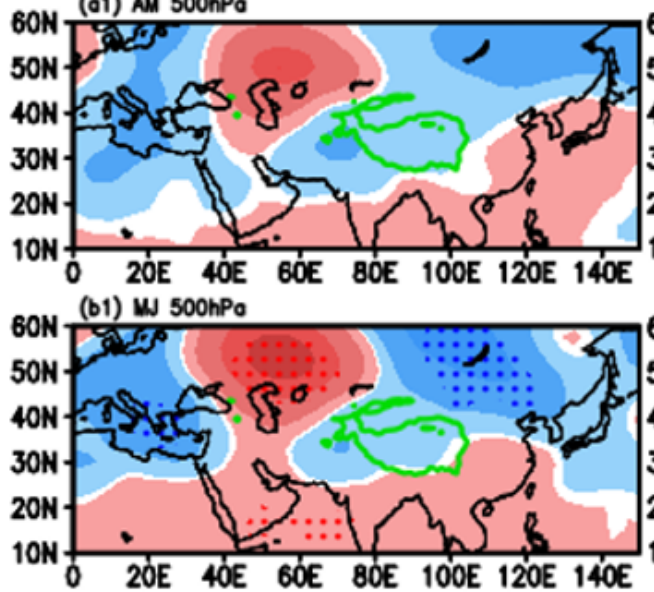

(c1) $\mathrm{N} 500 \mathrm{hPo}$

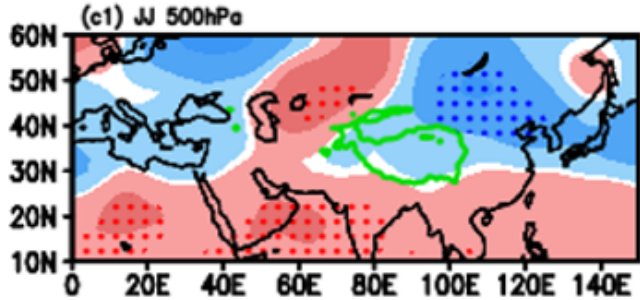

(d1) JA $500 \mathrm{hPa}$

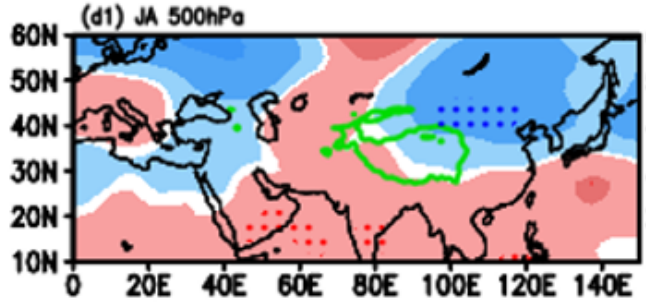

(c2) AM $300 \mathrm{hPa}$

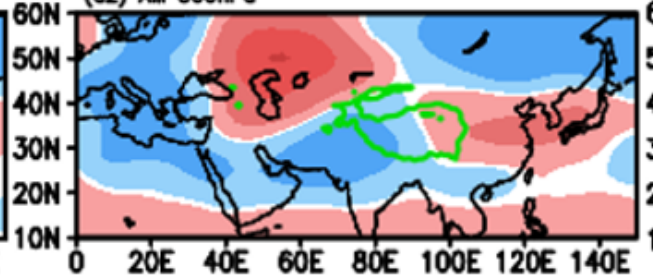

(b2) $\mathrm{WN} 300 \mathrm{hPa}$

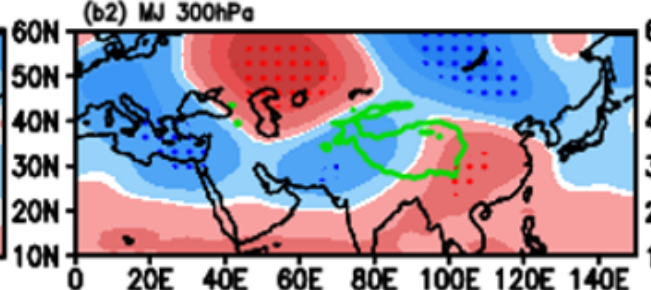

(c2) $\mathrm{N} 300 \mathrm{hPa}$

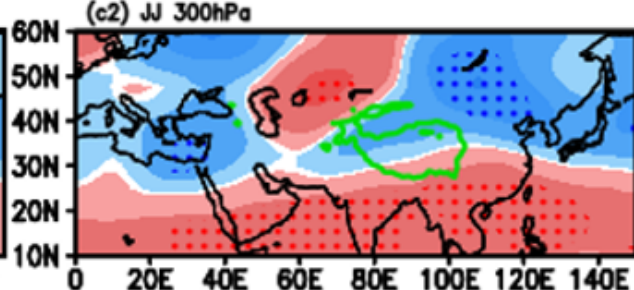

(d2) JA $300 \mathrm{hPo}$
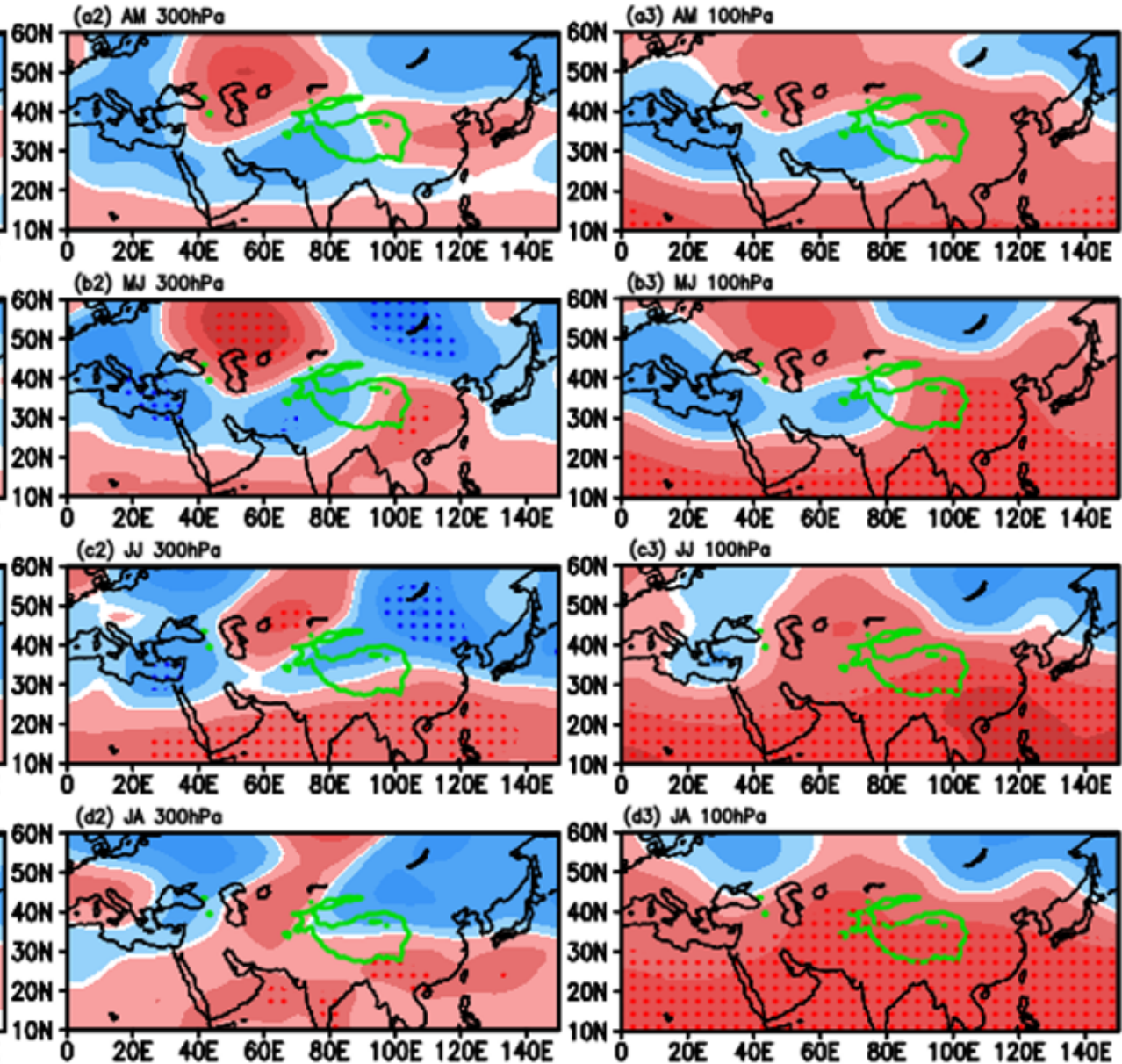

O 2OE 4OE GOE BOE 100E 120E 140E

(b3) MJ $100 \mathrm{hPa}$

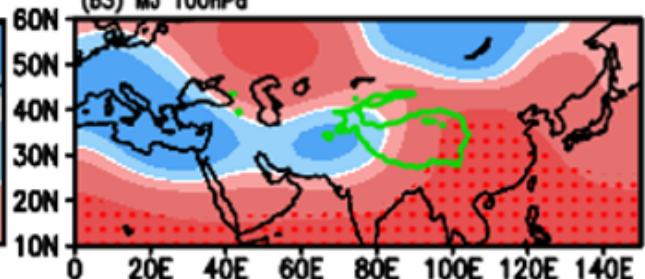

(c) $\mathrm{N} 100 \mathrm{hPa}$

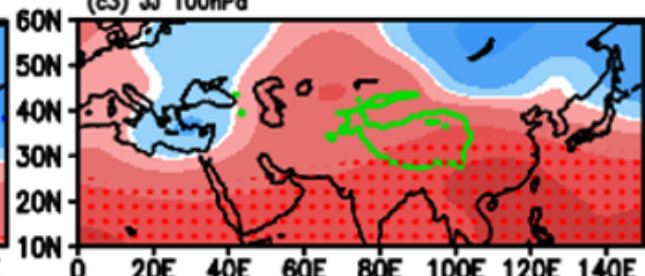

(d3) JA 100hPo

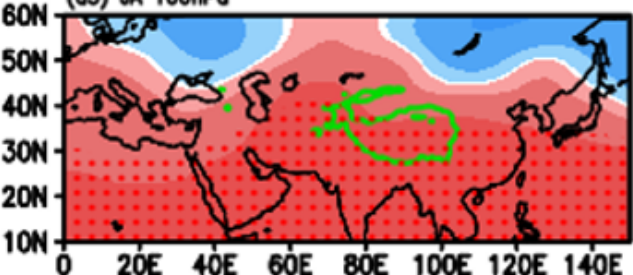

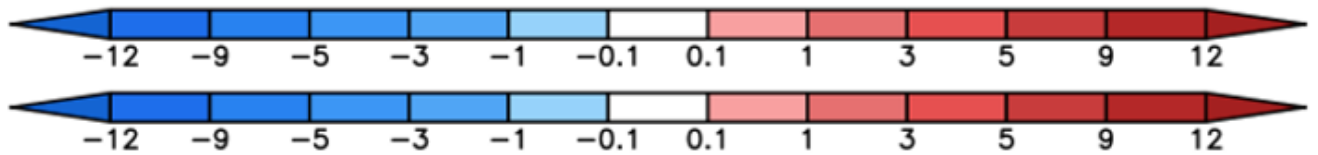

Figure 6

Regression fields between the average AM SSH over the CETP and the bimonthly geopotential height (units: dagpm) at 500-hPa, 300-hPa and 100-hPa in (a)AM, (b)MJ, (c) JJ and (d) JA. The green heavy solid curves in (a)-(d) denote the TP domain with altitude higher than 3,000 $\mathrm{m}$ a.s.l., and the stippled areas in (a)-(d) indicate correlation above the $95 \%$ confidence level. 

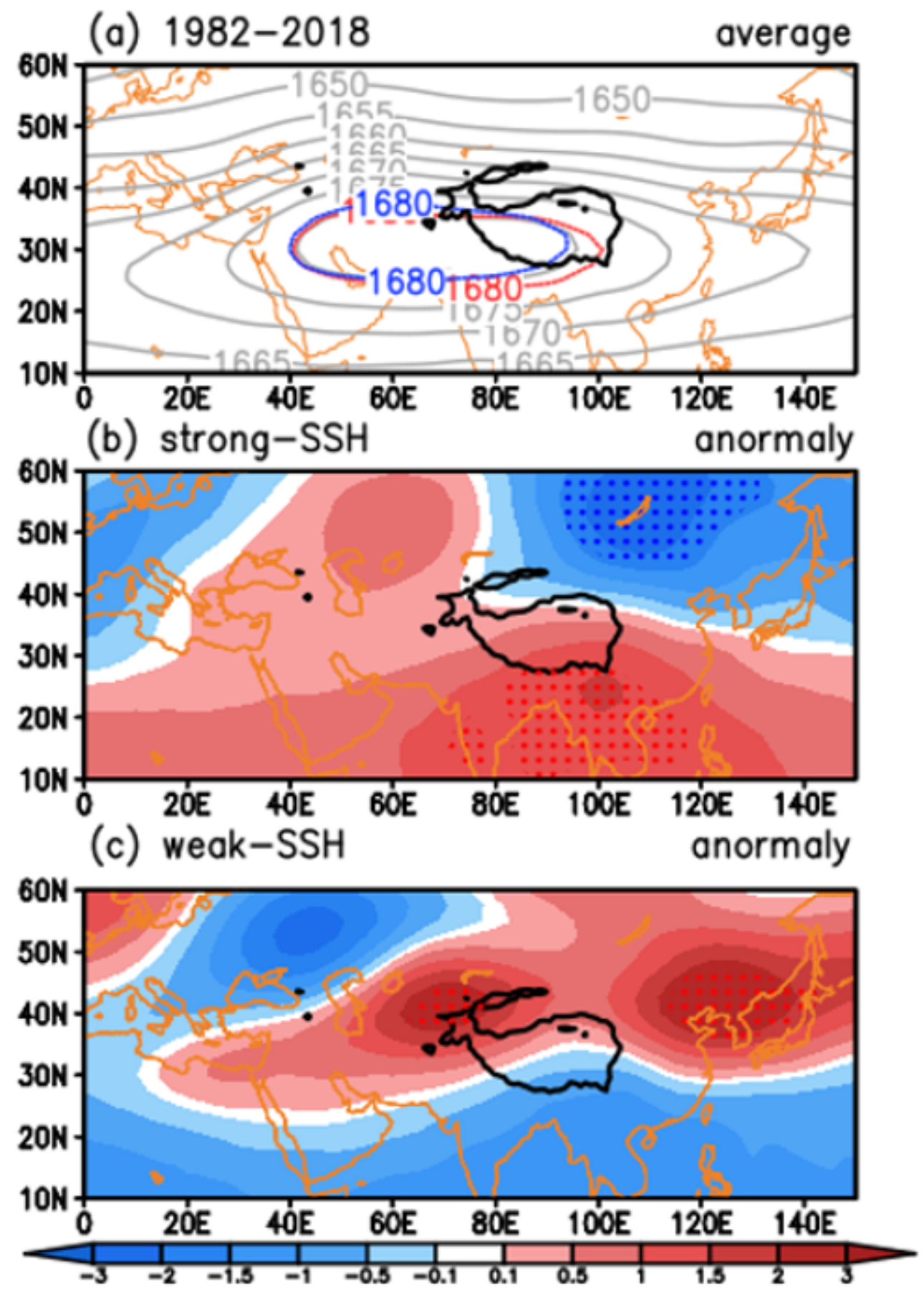

Figure 7

Distributions of summer average geopotential height (units: dagpm) at 100-hPa (a) during 1982-2018, and the composite geopotential height anomalies at 100-hPa in the years with (b) anomalous strong and (c) anomalous weak SSH than normal years in AM over the CETP. The red (blue) dashed line in (a) denote the location of SAH in the years with anomalous strong (weak) SSH than normal years in AM over the CETP. The black heavy solid curves in (a-c) denote the TP, and the stippled areas in (b) and (c) indicate anomaly above the $90 \%$ confidence level. 
(a) $1982-2018$

average
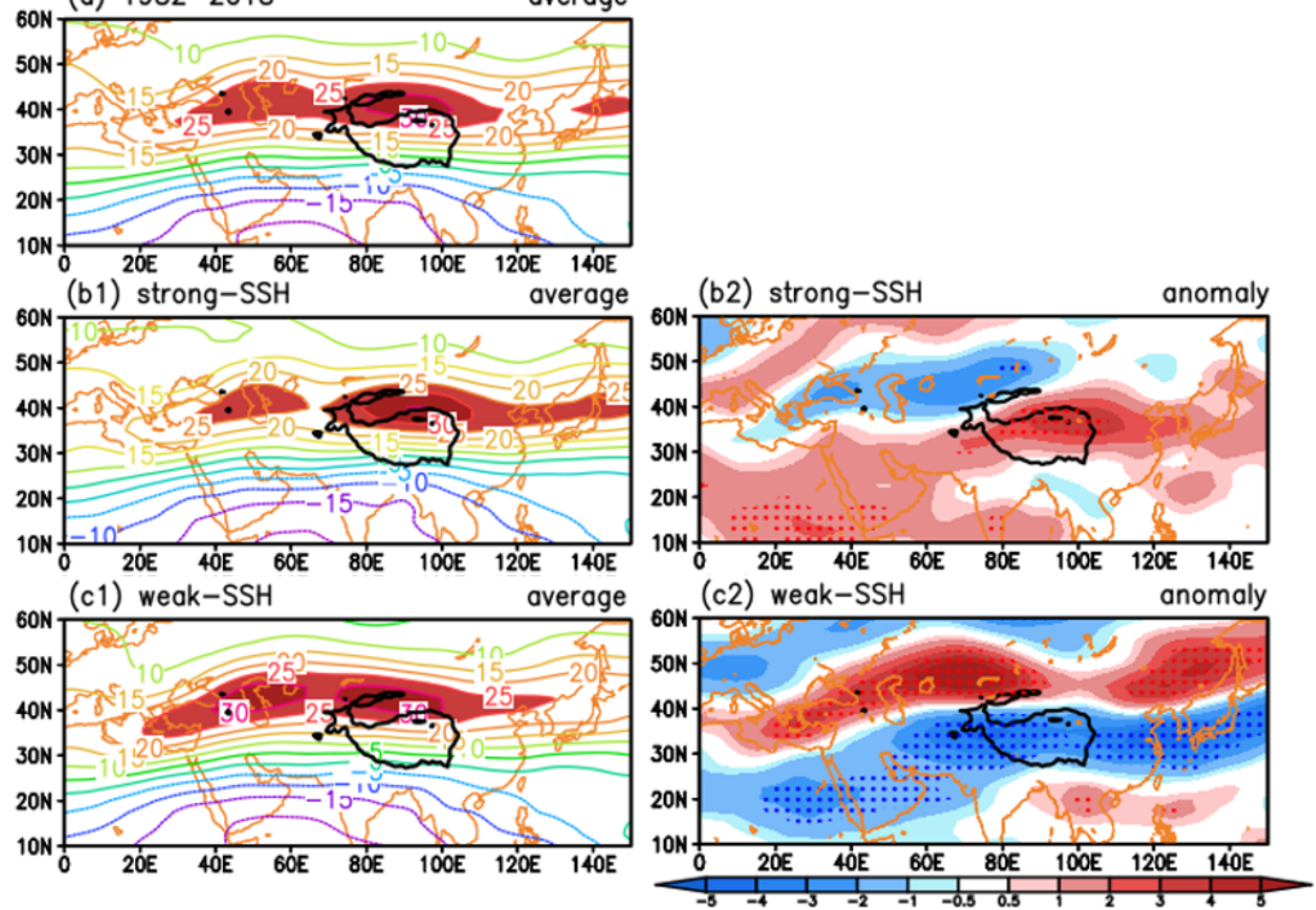

Figure 8

Distributions of summer average zonal wind (units: $\mathrm{m} \mathrm{s}-1$ ) at 200-hPa (a) during 1982-2018, and (b1, c1) the average and (b2, c2) the composite zonal wind anomalies at 200-hPa in the years with (b1, b2) anomalous strong and (c1, c2) anomalous weak SSH than normal years in AM over the CETP. The black heavy solid curves in (a)-(c) denote the TP, and the stippled areas in (b) and (c) indicate anomaly above the $90 \%$ confidence level. 

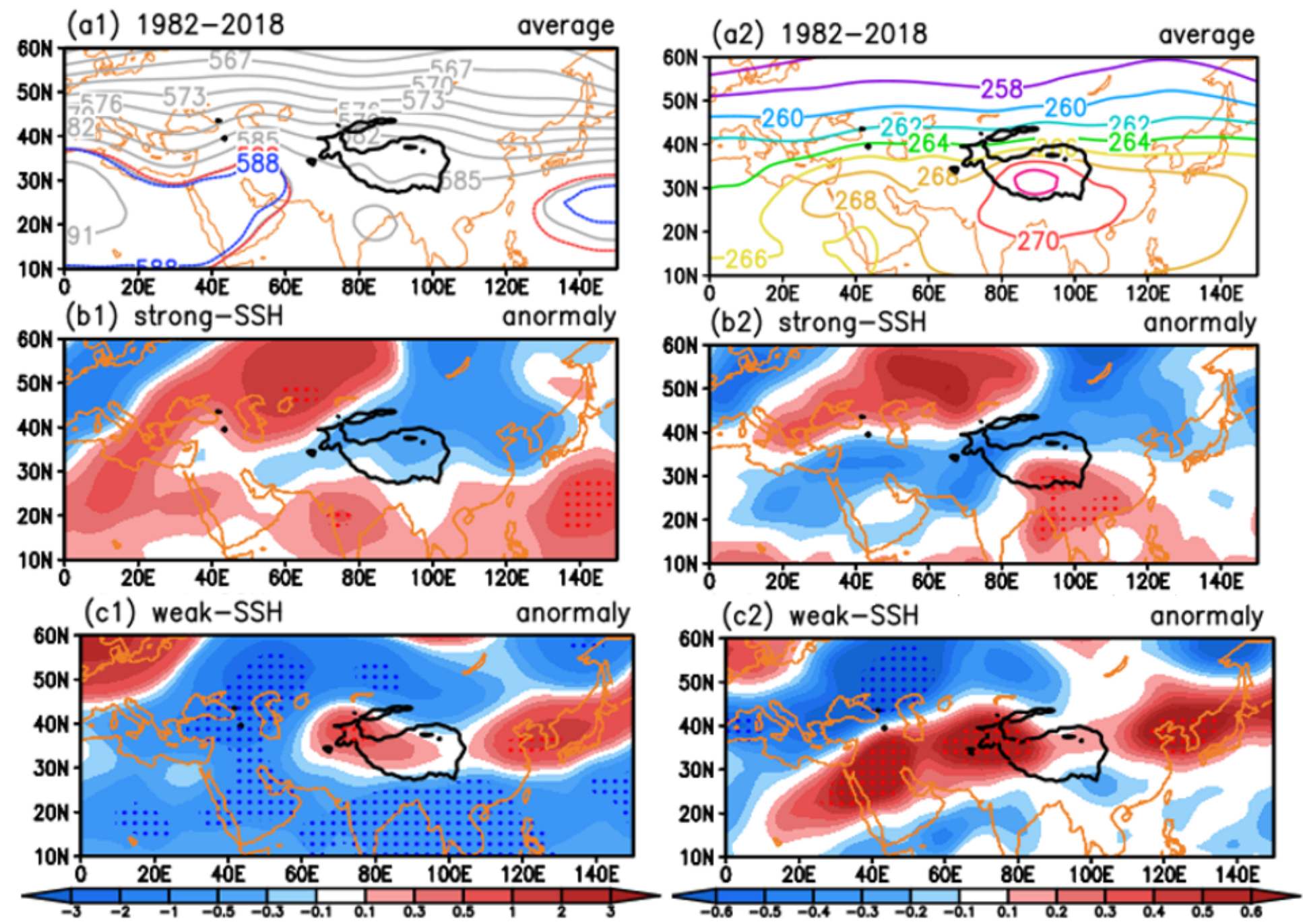

Figure 9

The same as Fig. 7, but for 500-hPa (a1-c1) geopotential height (units: dagpm) and (a2-c2) temperature fields (units: K). 


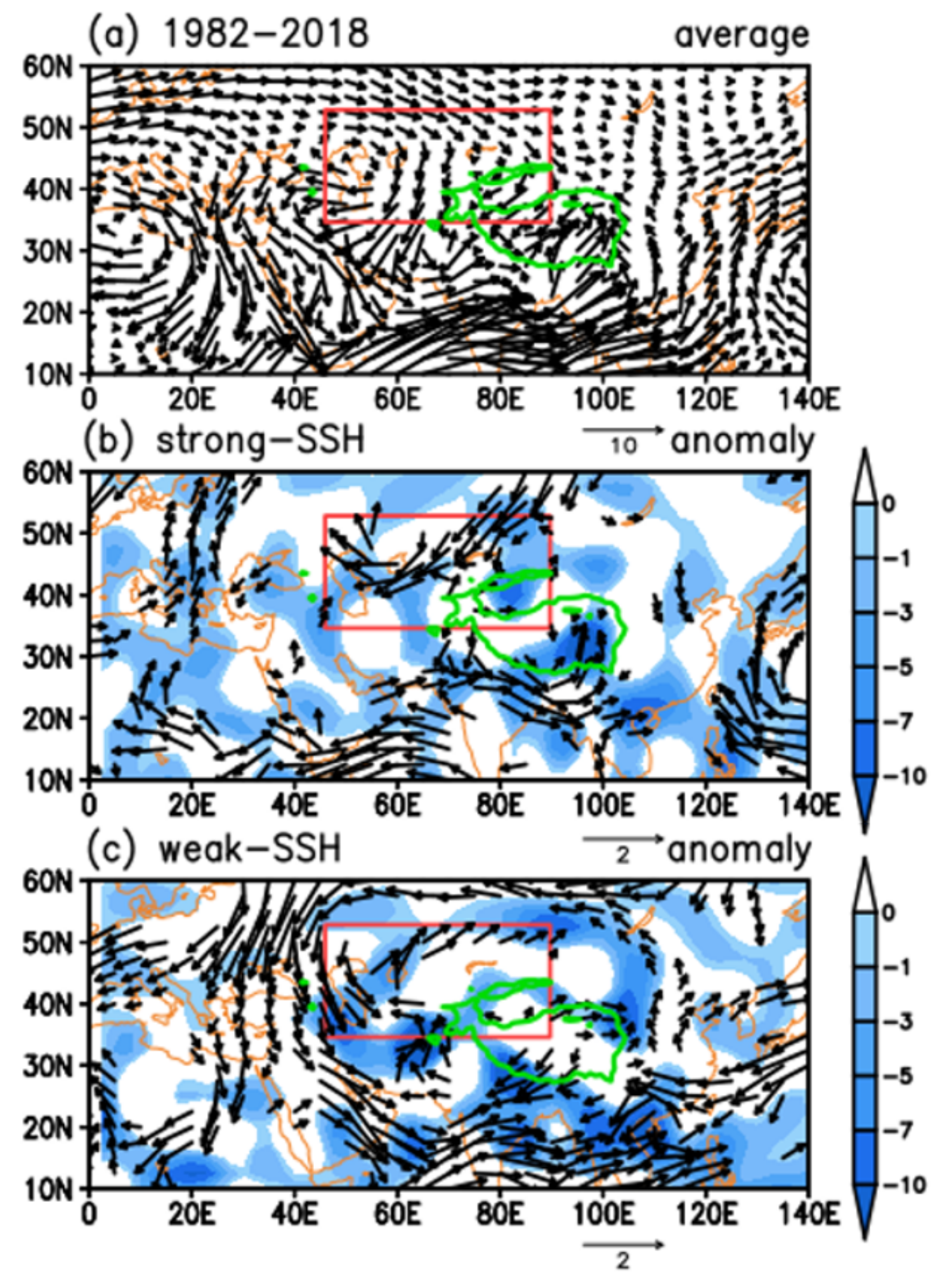

Figure 10

The same as Fig. 7, but for 850-hPa wind (units: $\mathrm{m} \mathrm{s}-1$, vectors) and its divergence (shading, 10-7 s-1). The black vectors in (b) and (c) denote anomaly above the $90 \%$ confidence level.

展

Figure 11 
The distributions of the moisture fluxes at (a) $925-\mathrm{hPa}$, (b) $700-\mathrm{hPa}$, (c) 500-hPa and (d) the vertically integrated from ground to 300-hPa (units: kg m-1 s-1) and their divergence (shading, 10-6 kg m-2 s-1) in the years with (a1, b1 , c1, d1) anomalous strong and (a2, b2, c2, d2) anomalous weak SSH than normal years in AM over the CETP. The black vectors in (a1-d2) denote anomaly above the $90 \%$ confidence level. 